\title{
The Past, Present, and Future of Power Electronics Integration Technology in Motor Drives
}

\author{
Thomas M. Jahns and Hang Dai
}

\begin{abstract}
The physical integration of power electronics and electric machines to form integrated motor drives (IMDs) eliminates the need for special enclosures and connecting cables in order to achieve mass, volume, and cost savings. The objective of this paper is to examine the future of integrated motor drive technology by first reviewing the history of IMD products from the 1960s to today, highlighting both the reasons for their success as well the significant technical obstacles that they had to overcome. Special attention is directed to the application of IMD technology to electric vehicle traction motor drives during the past 15 years. A long-term vision for IMDs is presented that calls for embedding the drive electronics directly inside the machine enclosure. In keeping with this vision, wide-bandgap (WBG) power semiconductor switches ( $\mathrm{SiC}$ and $\mathrm{GaN}$ ) offer exciting prospects for shrinking the size of power converters and simplifying their cooling requirements. New concepts for applying this WBG technology to IMDs are introduced, including revived interest in PWM current-source inverters. In the concluding section, a variety of other promising technologies are introduced that will be critical to realizing the full potential of integrated motor drives.
\end{abstract}

Index Terms-Current source inverters, high-temperature electronics, integrated motor drives, modular motor drives, power electronics integration, wide bandgap power semiconductors.

\section{INTRODUCTION}

$\mathrm{T}$ HE concept of combining an electric machine and power electronics into the same physical structure to form an integrated motor drive (IMD) is far from new. In fact, as discussed in this paper, precursors of today's integrated motor drives date back to the earliest days of solid-state power electronics, not long after the earliest generation of germanium and silicon power semiconductors appeared in the marketplace. Despite the significant number of IMDs that have been successfully commercialized since that time, integrated motor drives continue to occupy primarily niche applications that make up a small fraction of all of the applications served by conventional adjustable-speed motor drives.

Fig. 1 highlights some of the physical differences between conventional and integrated motor drives, providing a convenient launch point for discussing the principal motivations

Manuscript received August 18, 2017. This work was supported by the Wisconsin Electric Machines and Power Electronics Consortium (WEMPEC).

The authors are with the Department of Electrical and Computer Engineering, University of Wisconsin-Madison, Madison, WI 53706, USA (e-mail: jahns@engr.wisc.edu).

Digital Object Identifier 10.24295/CPSSTPEA.2017.00019

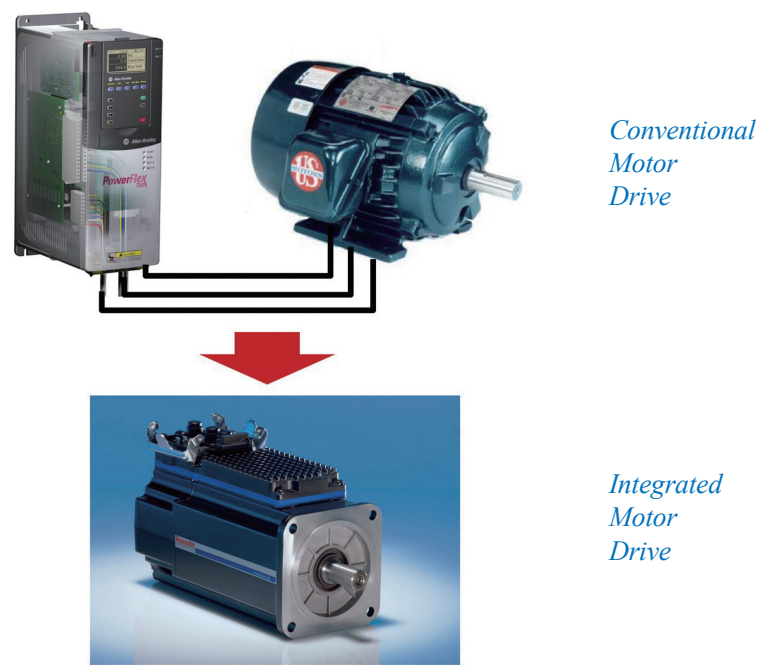

Fig. 1. Integrated motor drive concept contrasted with conventional drive (Image sources: Rockwell Automation, US Motors, Bosch Rexroth).

that continue to inspire broad interest in IMD configurations as candidates for new applications. For conventional motor drives, all of the control and power electronics (referred to henceforth as the drive electronics) is packaged in a separate housing structure that is connected to the machine by electrical cables. This configuration allows the drive electronics to be mounted in a convenient location and environment that may be separated from the machine by distances ranging from $<1$ meter to much longer distances $>1 \mathrm{~km}$. Motivations for adopting the IMD configuration with the machine and drive electronics in the same enclosure include the following factors, not necessarily in prioritized order:

- Reduced mass: A number of motor drive applications such as those in aviation (e.g., actuators, pumps, compressors) place a very high premium on mass minimization, so that eliminating the need for a separate drive enclosure and connecting cables is highly desirable.

- Reduced volume: Although closely related to the mass reduction objective, some applications such as electric hand tools place a very high priority on minimizing volume, making structural integration increasingly important as the tool power ratings grow.

- Higher efficiency: Many existing pump and fan drives continue to use fixed-speed, line-fed induction motors plus various forms of mechanical throttling to provide adjustable fluid and air flow rates. If these machines can be conveniently retrofitted with IMDs that fit into the same space as the machine without a separate drive enclosure, 
impressive system energy efficiency improvements that exceed $50 \%$ in some cases can be achieved that rapidly pay back the IMD's price premium.

- Lower cost: There are multiple potential paths to cost savings opened by IMDs. One of them is directly linked to the major system efficiency improvements described above that will significantly reduce the life cycle energy costs compared to fixed-speed operation, yielding cost savings that exceed the IMD's price premium. A second opportunity anticipates the day when the cost premium of the integrated power electronics needed in IMDs is exceeded by the cost of the eliminated enclosure and interconnecting cables in a conventional motor drive.

- Improved manufacturability: The opportunity to supply adjustable-speed motor drives packaged in a single assembly rather than two housings with interconnecting wire harnesses is very appealing to original equipment manufacturers (OEMs) of products such as automobiles and household appliances who are able to simplify their manufacturing process when installing the IMDs.

- Improved fault tolerance: As discussed in more detail later in this paper, the integrated motor drive concept lends itself to modular implementations and inverter topologies that hold promise for significantly improving the fault tolerance of the IMDs compared to conventional motor drives, particularly when PM synchronous machines are being used.

Although it is highly unlikely that all of these motivating factors would ever be present for any specific application, subsets of these factors appear sufficiently frequently in real-world motor drive applications that IMD-based solutions have been proposed, implemented, and successfully commercialized in a variety of special applications during the past 50 years. This success is particularly noteworthy since the limitations of power electronics during this period have generally worked to the disadvantage of the IMD implementation. This observation raises hope that advances in power electronics technology that are either now being commercialized or approaching on the horizon (see Section $\mathrm{V}$ and VI) will significantly improve the attractiveness of future IMD-based products.

The objective of this paper is to present a vision for the future of integrated power electronics applied to machine drives by reviewing the past, present, and future trends in integrated motor drive technology. Early landmark developments in the history of IMDs are reviewed in Section II, while Section III is devoted to reviewing more recent IMD developments that have appeared in traction drives for hybrid- and battery-electric vehicles during the past fifteen years leading up to the present.

Transitioning from retrospective to prospective, Section IV is devoted to presenting a vision for the future of IMD technology and a discussion of key technical challenges. Technology advances affecting all aspects of the IMD drive electronics are addressed in Section V, including major tech- nology trends that are destined to have an impact on several of these technical challenges. The expected impact of wide bandgap (WBG) power semiconductor technology on future IMDs is singled out for special attention. Progress towards developing the Integrated Modular Motor Drive (IMMD) concept is summarized along with a discussion of the potential benefits of adopting PWM current-source inverter topologies using WBG power switches in future integrated motor drives. Following a condensed review of some important technology developments that affect other components in the drive electronics, the paper concludes in Section VII with some final observations about the future of IMD technology, including the multi-disciplinary skills required of future power electronics and motor drive engineers in order to accelerate this development process.

\section{Milestones in IMD Development History}

This section is devoted to reviewing some of the milestone developments that have resulted in production IMD equipment during the past $50+$ years. A discussion of these noteworthy achievements serves to highlight both the motivations that inspired these integrated motor drives as well as the contemporaneous developments in power electronics technology that made these IMDs possible. These developments are presented in roughly chronological order in order to make it easier to identify the technology progression that made it technically feasible to develop more sophisticated IMDs as the years passed.

\section{A. Automotive Alternators (1960)}

The automotive alternator chosen for the first example actually does not qualify as an integrated motor drive, but it is included because it represents a critical precursor of the IMDs that follow in this section. More specifically, the power electronics consists of 6 (or more) diodes in an uncontrolled full-wave bridge configuration without any controlled power switches needed to synthesize variable-frequency ac voltage waveforms. The close linkage between automotive alternators and IMDs lies in the fact that these diode devices are mounted inside the alternator housing in close proximity to the Lundell claw-pole synchronous alternator

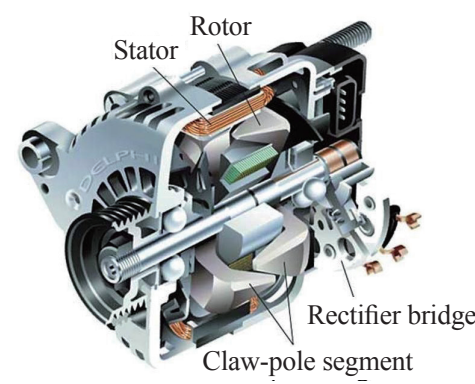

(a)

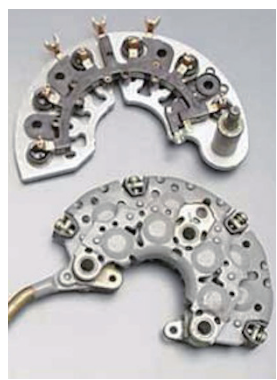

(b)
Fig. 2. Modern automotive alternator: (a) cutaway view; (b) 2 production rectifier units [1]. 
machine, exposing them to the elevated thermal and vibration conditions that accompany this mounting configuration. A cutaway view of a typical modern automotive alternator is provided in Fig. 2(a) and Fig. 2(b) provides a view of two different production versions of the rectifier units [1]

Chrysler installed the first production automotive alternators into their 1960 Valiant model, which occurred only approximately 5 years after silicon power diodes first became commercially available. Despite the early production state of these diode devices, they were packaged in metal cans that allowed them to operate reliably with case temperatures up to $160^{\circ} \mathrm{C}$. Today's silicon diode rectifier installed in automotive alternators have maximum operating case temperatures of $200{ }^{\circ} \mathrm{C}$. The power ratings of these alternators have also increased substantially from less than $500 \mathrm{~W}$ in the $1960 \mathrm{~s}$ to $>1.5 \mathrm{~kW}$ today. The resulting thermal management challenges are significant, resulting in modern designs using either forced air or liquid cooling. The commercial success of these automotive alternators is truly impressive, with total cumulative production numbers that are conservatively estimated to be in the range of hundreds of millions [2].

\section{B. Electronically-Commutated Motor (ECM) Blower Fan Drive (1987)}

One of the first major IMD products developed for residential use in Heating, Ventilating and Air Conditioning (HVAC) applications was the Electronically-Commutated Motor (ECM), first released as a product by GE in 1987 [3]. The ECM was designed for use in residential and light commercial HVAC products such as furnace blowers where they provided a means of improving overall furnace system efficiency and comfort by providing adjustable-speed air flow to the living spaces instead of conventional on-off thermostat-based control with a fixed-speed blower. The basic configuration of the ECM consists of a PM synchronous motor mounted in its own housing with two end bells, attached to a cylindrical shell having the same diameter as the motor housing that contains all of the drive electronics. Fig. 3 provides both a transparent view of the ECM in Fig. 3(a), and a view of the ECM drive electronics in Fig. 3(b) [4]. ECM products were developed with several power ratings that fell in the range between $300 \mathrm{~W}$ and $1 \mathrm{~kW}$.

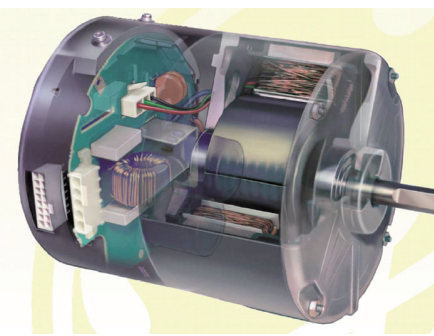

(a)

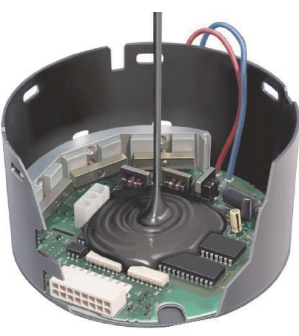

(b)
Fig. 3. Electronically-Commutated Motor (ECM) showing: (a) a transparent view of the ECM; and (b) a view of the ECM drive electronics mounted in a concentric shell housing [4].
As indicated in Fig. 3(a), the ECM uses a surface PM machine with ferrite magnets. The machine stator incorporates concentrated windings that deliver trapezoidal back-emf waveforms so that the motor can be excited as a so-called brushless dc machine with six-step current waveforms. This configuration offers advantages for simplifying the control algorithm and sensor requirements, making it possible to use the zero-crossings of the back-emf voltage waveforms for rotor position sensing.

Fig. 3(b) reveals that the ECM was designed to use mostly discrete parts including 6 transistor switches (plus anti-parallel diodes) in individual TO-220 packages that are clamped to the side of the shell housing for air cooling.

Other competitors responded with their own versions of ECM blower drives that, in some cases, used induction machines instead of PM machines. Unfortunately, the ECM products were not immediately embraced by the HVAC industry due to a combination of factors including early reliability problems and an initial lack of receptiveness by HVAC equipment distributors and field repair staff. Eventually these problems were overcome, and ECM-class IMDs are now being widely accepted by the HVAC industry in North America in many of their products including air handlers, furnaces, heat pumps, air conditioners, and refrigeration equipment.

\section{Submersible Water Pump (1999)}

Grundfos, an international pump manufacturer with headquarters in Denmark, was responsible for another milestone in the history of IMD engineering when they developed and installed an integrated motor drive into one of their submersible water pump products that was introduced into the marketplace in 1999. Adoption of an adjustable-speed motor drive made it possible for Grundfos to deliver constant water pressure to the users in spite of changes in the water flow demand. Mounting the motor and the drive in the submersible pump unit underground made it possible to simplify the power cabling required in the well shaft while using the pumped water as a plentiful and effective coolant for the motor and the drive electronics [5].

Developing the IMD for this application required it to be designed to fit in a cylindrical tube with a diameter of $7.6 \mathrm{~cm}$ (Fig. 4). A high-speed surface PM synchronous motor was selected for this special application, and a "wet rotor" design was adopted that required the water to flow through the full length of the machine in the airgap, cooling both the stator and rotor in the process. A compact implementation of the drive electronics was achieved by means of a custom-designed (1 or $2.2 \mathrm{~kW}$ ) hybrid integrated circuit that incorporated a threephase inverter, single-phase rectifier, and power factor correction stage. This hybrid circuit module was mounted on an arcshaped heat sink that adhered to the stainless steel pump casing tube, taking advantage of the cooling capacity of the pumped water that flowed over its surface. Although the IMD unit raised the cost of the unit, the constant-pressure capabilities that it provides have made it a success in the 


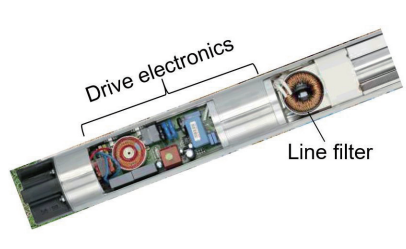

(a)

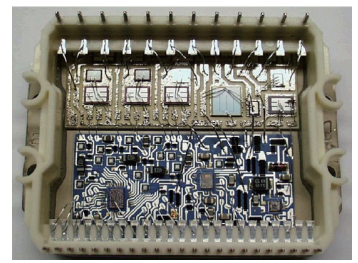

(b)
Fig. 4. Grundfos submersible pump: (a) cutaway view of pump unit showing key IMD components ; and (b) Hybrid integrated circuit containing inverter, rectifier, and power factor correction power electronics (Source: Grundfos).

marketplace since it was first introduced in 1999.

\section{High-Speed Chiller Compressor (2000)}

In the early 2000s, a high-speed chiller compressor product was introduced into the HVAC marketplace that incorporated an integrated motor drive as a key component. The chiller unit was manufactured by Turbocor, an Australian company, and developed in partnership with CSIRO (Commonwealth Science and Industrial Research Organization), an agency supported by the Australian federal government. This product represents a significant milestone in the commercial/industrial refrigeration business because it demonstrated the ability to significantly shrink the chiller mass and

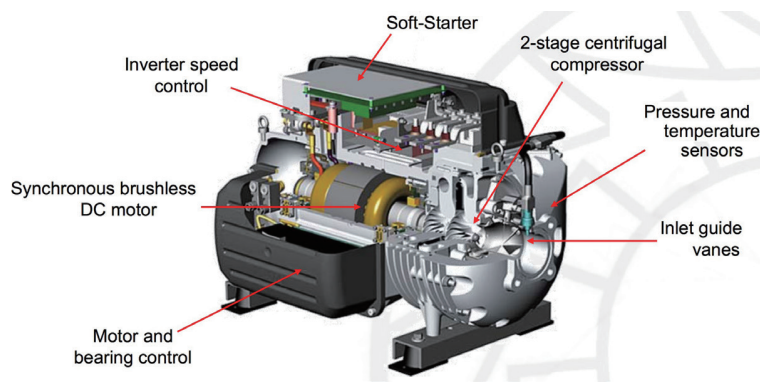

(a)

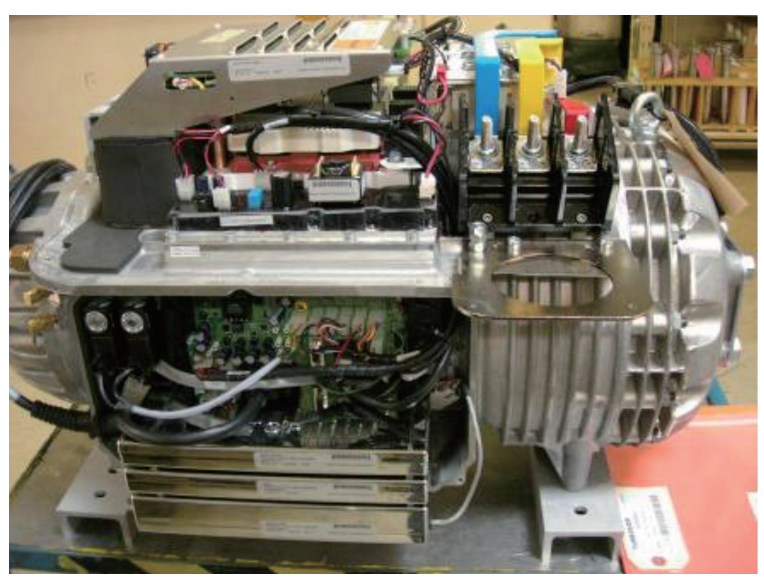

(b)

Fig. 5. Danfoss Turbocor chiller compressor: (a) Cutaway view of compressor unit identifying key components including IMD subassemblies; (b) Partially disassembled compressor exposing drive electronics [6]. volume by replacing a lower-speed $(<5000 \mathrm{rpm})$ reciprocating, screw, or scroll compressor with a high-speed centrifugal compressor designed for operation at 48,000 rpm [6].

A high-speed PM synchronous machine is mounted on the same shaft as the compressor (i.e., no gearbox) and the drive electronics is wrapped around the machine to form the IMD as shown in Fig. 5. Air and water are used for cooling in different models of the chiller that are available with ratings up to $700 \mathrm{~kW}$ (200 ton cooling) from Danfoss Turbocor. Another innovative feature of this chiller is the use of magnetic bearings for suspension, giving the chiller the special distinction of being oil-free. In addition to the mass/volume reduction, the combination of centrifugal compressor and adjustable-speed capability makes it possible for these chillers to deliver significant improvements in their Coefficient of Performance (COP) values under partial-load conditions compared to conventional chillers using screw compressors.

\section{E. Industrial-Grade Integrated Motor Drives (1990s to To- day)}

During the past 25 years, a number of manufacturers of conventional motor drives have developed integrated motor drive product lines intended for general-purpose industrial applications including pumps and fans/blowers that derive performance improvements and energy cost savings benefits from adjustable-speed operation. These units can vary significantly in shape and volume, but nearly all of them adopt a relatively conservative IMD configuration in which the drive electronics is mounted in an enclosure that is physically attached to the machine frame. As a result, the drive is easily visible as an appendage to the machine it is exciting (see Fig. 6). Advantages of this design approach include the fact that the drive electronics is isolated more completely from the thermal and vibrational challenges imposed by the machine compared to IMD designs in which the drive electronics is integrated inside the machine housing.

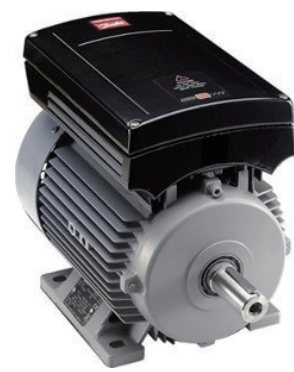

(a)

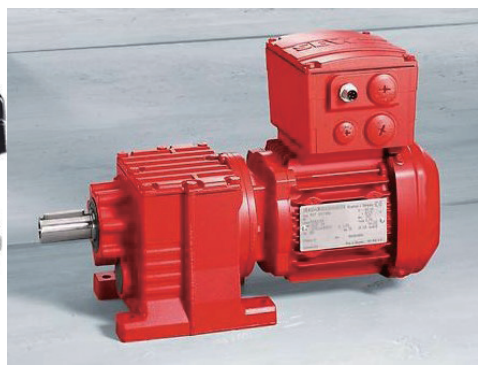

(b)
Fig. 6. Examples of IMD products for industrial pump/fan/blower applications: (a) Danfoss VLT DriveMotor [7]; (b) SEW Eurodrive MOVIMOT gearmotor product incorporating gearbox together with IMD [8].

Since these IMD units are intended for use with conventional pumps and fans, induction machines are typically adopted for their designs with ratings from 0.5 to $10 \mathrm{~kW}$, although product offerings using PM synchronous machines are also available. Combining the motor and drive into the 
same assembly is appealing to industrial customers who would like to retrofit existing fixed-speed pumps and blowers with adjustable-speed capabilities, without having to worry about finding separate wall or floor space for mounting a conventional stand-alone motor drive.

Although these industrial IMD units have been available for many years, their commercial success has been rather limited when considered as a fraction of all industrial motor drives for pump and fan applications sold each year with ratings less than $10 \mathrm{~kW}$. The reasons for their limited marketplace success are varied, but it is generally acknowledged that many potential customers are concerned that the drive electronics will fail long before the machine, making it necessary for customers to pay the higher cost of replacing both the machine and the drive whenever a drive failure occurs. While it can be argued that the justification for this concern is getting weaker each year as drive reliability continues to improve with time, it nevertheless highlights the fact that high temperature and vibration are almost always among the most difficult technical challenges faced by IMD designers. Stated differently, the act of purposely mounting the drive electronics in close physical proximity to the machine significantly aggravates the challenge of designing IMD products that can meet increasing customer expectations for higher reliability in the motor drives that they purchase.

\section{F. Industrial Automation Servo Drives (2006)}

Industrial automation servo drive applications offer an attractive opportunity for IMDs to demonstrate and capitalize on the special advantages that they can offer. Using the conventional approach, an automated manufacturing line with many servos has a separate drive unit for each servomotor, and these drive units are all mounted together in a cabinet, requiring a separate set of multi-phase electrical cables to connect each motor to its dedicated drive. However, if each servomotor is co-packaged with its drive electronics, then only dc power and the servo commands have to be distributed to each of these integrated servomotors. Since large numbers of servomotors can draw their dc power from the same bus in a "daisy-chain" configuration (Fig. 7(a)), the reduction in required cabling between the controller cabinet and all of the servomotors can be significantly reduced, saving cabling cost, mass, and volume, as well as valuable installation time and cost. This opportunity makes the IMD approach particularly attractive and cost-effective for manufacturing automation applications [9].

In 2007, Bosch Rexroth introduced their IndraDrive Mi product line that integrates high-performance PM synchronous servo machines with their drive electronics into compact IMD configurations (Fig. 7(b)). Although the servomotor and the drive electronics are actually separate units, they have been designed for convenient interconnection into a tightly packaged configuration. While the motor itself can be cooled by natural convection, forced air ventilation, or liquid, depending on the model selection, the drive electronics unit is mounted on one of four axial surfaces of the machine frame that serves as the heat sink for dissipating the power converter losses. The IndraDrive power electronics is capable of delivering peak output power values up to approx. $12 \mathrm{~kW}$. The IndraDrive servo product line has been sufficiently successful that it has motivated competing servo manufacturers to develop their own IMD-based servo drives.

\section{G. Hand Dryer Air Blower (2013)}

The final IMD-based commercial product highlighted in this section is the Airblade Tap hand dryer developed by Dyson Ltd and first introduced in 2013 (Fig. 8(a)). At the heart of the powerful air blower is a $1.6 \mathrm{~kW}$ high-speed surface PM synchronous machine that spins at 100,000 $\mathrm{rpm}$, resulting in a very compact integrated air blower unit including the motor, drive electronics, and blower impeller that fits inside an $85 \mathrm{~mm}$ diameter cylindrical shell (Figs. 8b and $8 \mathrm{c}$ ). The single-phase H-bridge inverter used to excite this machine is built on a printed circuit board mounted immediately below the machine to form an IMD. The blower unit is designed to accelerate the impeller from 0 to 90,000 $\mathrm{rpm}$ within $0.7 \mathrm{sec}$, and deliver an airflow speed of $717 \mathrm{~km} / \mathrm{h}$ during full-speed operation at 100,000 rpm [10].

While the high speed and resulting high power density of this air blower IMD gives it some unique performance characteristics, several of its basic layout and construction features are similar to those found in other IMDs developed for use in a variety of other residential and commercial applianc-

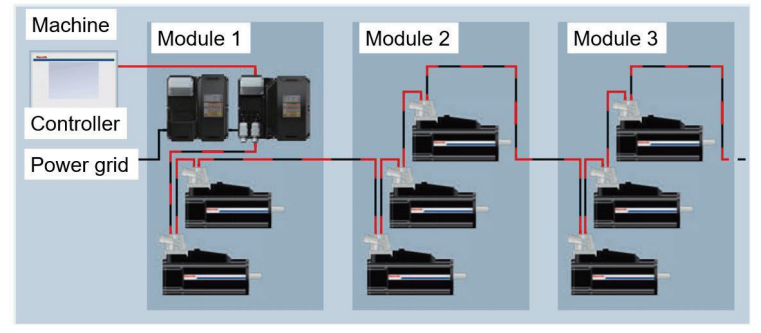

(a)

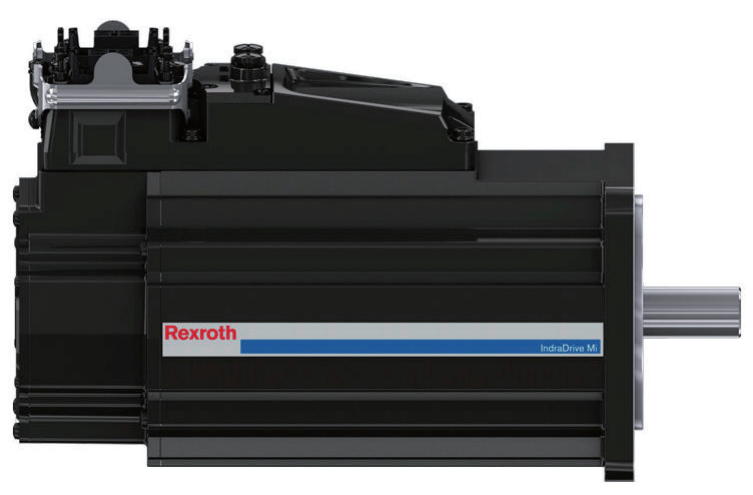

(b)

Fig. 7. IMD used in factory automation servo drives: (a) Servo drive interconnection scheme using only a single cable to distribute both de power and communications; (b) Bosch Rexroth IndraDrive Mi servo [9]. 


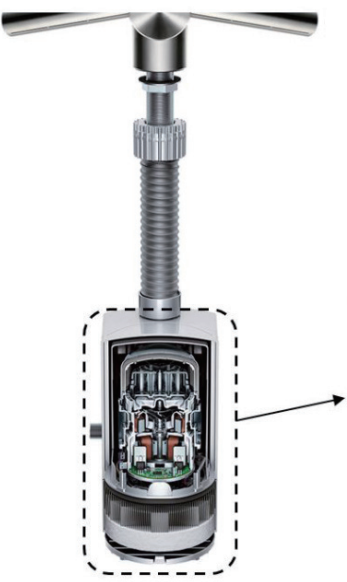

(a)

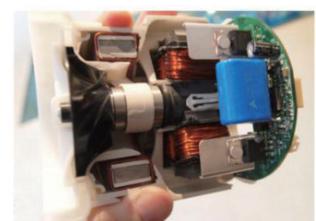

(c)

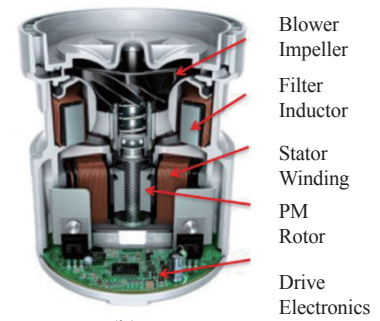

(b)
Fig. 8. High-speed hand dryer blower unit: (a) Cutaway drawing of Dyson Airblade Tap hand dryer; (b) Cutaway drawing of $1.6 \mathrm{~kW}$ blower IMD unit including impeller; (c) View of cutaway blower hardware [10].

es. For example, many types of refrigeration units require circulating fans with low power ratings $<0.75 \mathrm{~kW}$ that are appealing candidates for IMD implementations. Packaging the drive electronics in the same enclosure as the motor and blower enables major suppliers to sell integrated blowers to large appliance original equipment manufacturers (OEMs) that can be easily and quickly installed as single units during the appliance manufacturing process, rather than as separate motor and drive units connected by an electrical cable. This is a trend that is likely to continue growing during coming years in a variety of manufactured goods including hand tools and automotive accessories in addition to appliances.

\section{ReVIEW of IMD DeVELOPMENTS For Automotive TRACTION DRIVES}

One of the application areas that has actively motivated the development of several new integrated motor drive concepts at high power levels $>25 \mathrm{~kW}$ during recent years has been traction motor drives used in the powertrains of hybridand battery-electric automobiles. This section is devoted to reviewing several of the most noteworthy IMD technology developments for the powertrains of on-road electrified vehicles during the past 15 years that help to highlight both the motivating factors for IMD adoption as well as the likely directions for future IMD technology development.

\section{A. Merging of Powertrain Hardware with Drive Electronics}

When it was introduced in the late 1990s, the Toyota Prius adopted a configuration that mounted all of the hybrid powertrain control electronics into a dedicated enclosure that is separated from the engine, two PM machines, and planetary gear assembly that comprise their power-split powertrain architecture, as shown in Fig. 9(a). This required large electrical power cables and heavy-duty connectors to link these two

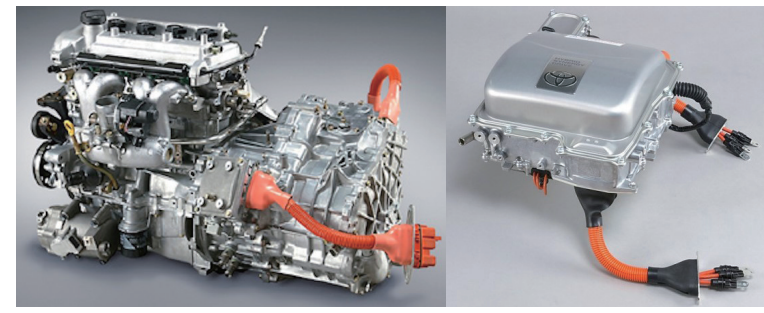

(a)

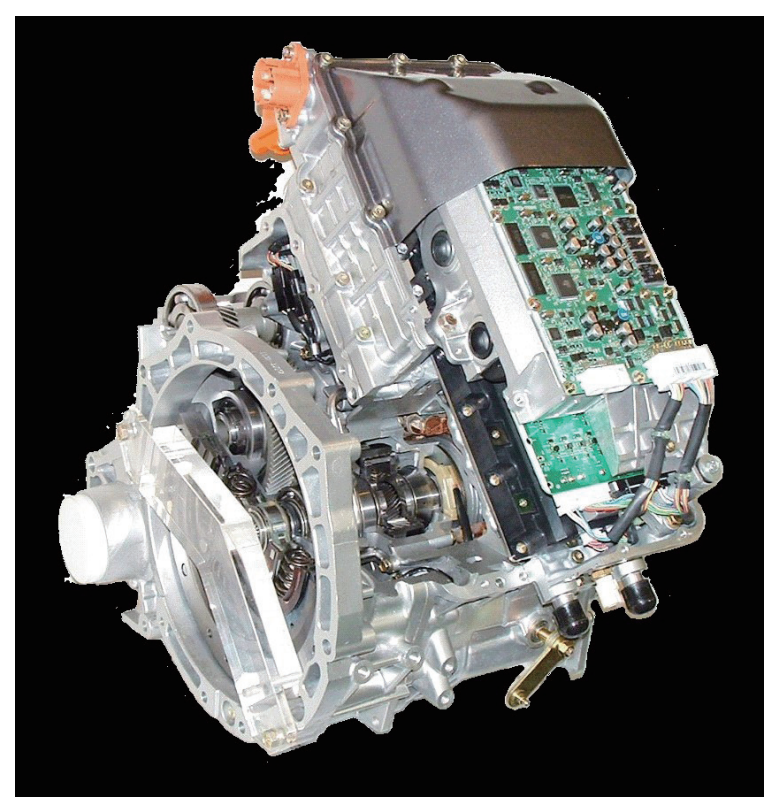

(b)

Fig. 9. Hybrid power-split integration evolution: (a) 2000 Toyota Prius configuration with separate powertrain hardware and controller enclosures; (b) 2004 Ford Hybrid Escape with integrated powertrain and drive [11].

assemblies that are very apparent in Fig. 9(a), resulting in a negative impact on both the powertrain cost and reliability.

Ford Motor Co. worked with Aisin Seiki, a major Japanese automotive supplier partly owned by the Toyota group, to develop the powertrain transaxle for the 2004 Ford Hybrid Escape that used the same basic power-split architecture as the Prius. However, the enclosure for the powertrain control electronics was combined with the housing for the rest of the powertrain hardware to form a single merged transaxle assembly, as shown in Fig. 9(b). The inverters for the two interior PM machines have a combined peak power rating of $115 \mathrm{~kW}$. The power electronics is cooled by water and the two machines are cooled by automatic transmission fluid (ATF), with a heat exchanger between the two coolant fluids integrated into the transaxle assembly. Rubber vibration isolators were used to help protect the powertrain control electronics from excessive engine vibration [12].

Advantages of the merged transaxle design include elimination of the external power cables and connectors that were required in the Prius configuration discussed above. The merged transaxle configuration used in the Ford Hy- 
brid Escape was sufficiently successful that the same basic configuration was adopted again in the Ford Hybrid Fusion introduced four years later in 2008.

In more recent years, this trend towards merging the powertrain hardware and electronics into the same assembly enclosure has been occurring in other electrified vehicles as well. One documented example of this evolution is the development of the second-generation powertrain for the Nissan Leaf battery-electric vehicle. Like the Toyota Prius, the first-generation Leaf introduced in 2011 used separate enclosures for the powertrain hardware and electronics, connected by an external power cable. The second-generation Leaf powertrain introduced two years later in 2013 merged the two enclosures together to eliminate the external cable, as shown in Fig. 10. Nissan engineers have described that an additional advantage of this re-design was a net reduction in the total electric powertrain mass by $>10 \%$ [13].

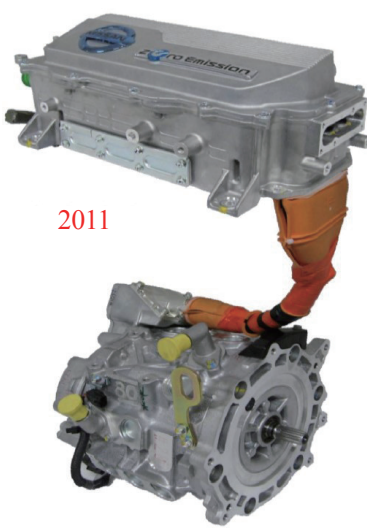

(a)

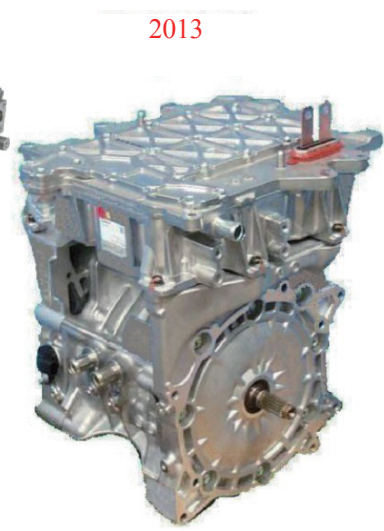

(b)
Fig. 10. Evolution of Nissan Leaf powertrain hardware and control electronics to integrated assembly in 2nd generation (2013) design [13].

Another example of current trends in the evolution of electric powertrain designs towards IMD architectures is the Tesla Model S powertrain that was first introduced in 2012. The powertrain for the Model S battery-electric vehicles (Fig.11(a)) was developed as a rear-wheel-drive transaxle assembly consisting of two cylindrical housings with almost the same diameter and length, one for the induction machine and the other for the inverter, with the geartrain assembly

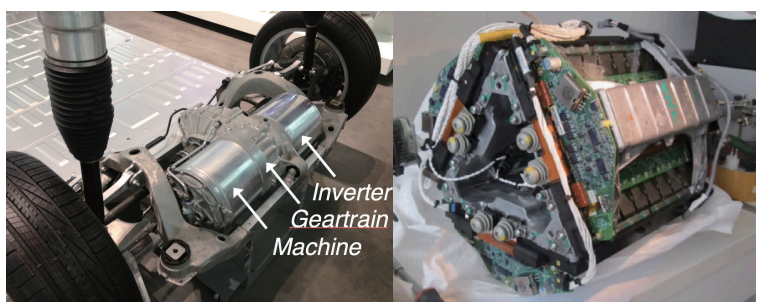

(a)

(b)

Fig. 11. Tesla Model S battery-electric vehicle powertrain: (a) Rear axle powertrain transaxle layout [14]; (b) Cylindrical 3-phase $325 \mathrm{~kW}$ (peak) inverter without housing [15]. sandwiched between them. The motor and inverter are both rated for $325 \mathrm{~kW}$ peak power.

\section{B. In-Wheel Traction Motor Drive (2006)}

A more aggressive approach to applying IMD principles has been taken by engineers at Protean Electric in the process of developing an in-wheel motor traction drive. The in-wheel traction architecture differs significantly from that of electric vehicles currently in production because the traction motor is mounted directly inside the wheel hub so that it directly delivers its torque and power to the wheel without needing any transaxle shaft or gearbox. Although the idea of in-wheel traction drives is not new, Protean has been among the most active companies during the past several years developing engineered prototype traction drives that it has used to attract partners/customers for vehicle production opportunities.

Fig. 12 provides rendered drawings of the Protean inwheel traction drive, including both a cutaway view and an exploded view of their in-wheel drive unit. The unit uses an inside-out surface PM machine with the rotor magnets mounted along the inner circumference of the hub on which the vehicle's wheel is mounted. The Protean in-wheel motor is capable of delivering $1000 \mathrm{Nm}$ of torque and $75 \mathrm{~kW}$ of power to the wheel. The stator that excites the spinning rotor hub assembly takes the form of an annular laminated steel core mounted inside the hub. Stator windings are mounted in stator core slots and these windings are excited by an inverter in the early prototype units that is designed to fit inside and adjacent to the annular stator core. In this configuration, the drive electronics has to be sufficiently rugged to survive the hostile environment inside the wheel hub, including very high g-forces, both high and low temperature extremes, as well as exposure to the high levels of dirt, water, and vibration that define typical road conditions [18].

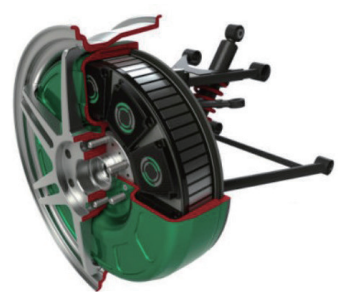

(a)

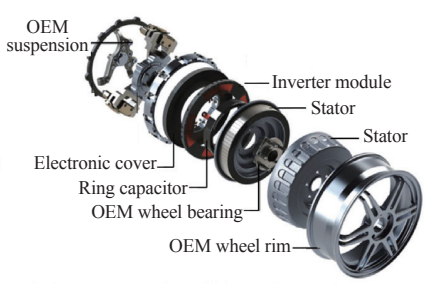

(b)
Fig. 12. Protean Electric in-wheel traction drive: (a) Rendered cutaway drawing of assembled $75 \mathrm{~kW}$ unit [16]; (b) Rendered exploded view of key components that comprise the in-wheel traction drive [17].

The in-wheel traction drive architecture offers vehicle designers a combination of both intriguing performance opportunities and challenges that continue to draw attention and debate in the automotive engineering community, but no consensus. While it is uncertain whether the Protean inwheel traction drives will achieve commercial success, the ambitious nature of their IMD-based design helps to inspire 
and challenge traction drive designers about the technical feasibility of this approach and the problems that remain to be fully addressed.

\section{Integrated Traction Motor Drives}

There is growing evidence that automotive traction drive suppliers are taking the integrated motor drive more seriously in their future product plans. An example is the SIVETEC line of traction drive products developed by Siemens. In 2014 the SIVETEC MSA 3300 integrated motor drive was announced with a power rating of $60 \mathrm{~kW}$. Two views of this IMD are provided in Fig. 13, showing the unit both with and without a metal cover over the drive electronics. Comparing this IMD with the earlier examples of merged powertrain hardware and controller units already in production (Figs. 9(b) and 10), some differences are apparent in their appearances: 1) the size of the drive electronics compared to the machine it excites has been reduced noticeably in the newer MSA 3300 unit compared to the Ford and Nissan units; and 2) the extent of the physical integration of the power electronics with the machine is tighter in the MSA 3300 unit.

In addition to these differences that are externally visible, the power electronics in the MSA 3300 is built using power modules in which the power semiconductors are sintered rather than soldered, and wire bonds are replaced with planar interconnect technology [20]. Both of these changes are important steps in the direction of further ruggedizing the power electronics to improve its reliability in more demanding thermal and vibration environments that are typical of IMDs.

Available information from Siemens indicates that their SIVETEC integrated motor drive technology is available using either PM synchronous or induction machines with drive ratings up to $200 \mathrm{~kW}$. This IMD technology has been adopted for use in two of Volvo's vehicles: the XC90 T8 plugin hybrid sport-utility vehicle, and the $\mathrm{C} 30$ battery-electric hatchback vehicle. Neither of these vehicles are in largescale production as of this writing. Despite the uncertainty about the future production plans for these motor drives, the SIVETEC MSA 3300 represents a significant milestone in the development of integrated motor drive technology for electrified vehicle powertrain applications.

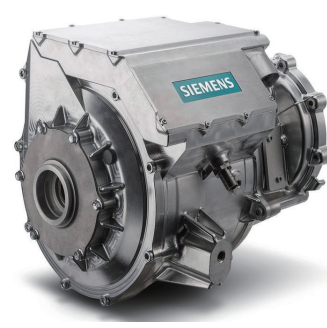

(a)

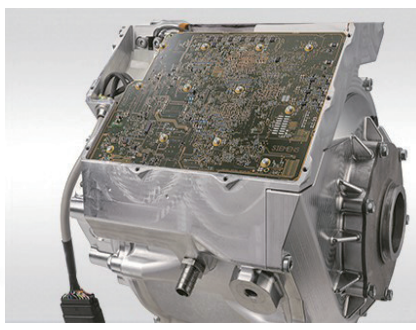

(b)
Fig. 13. Siemens IMD technology for EV traction drives: (a) View of 60 kW SIVETEC MSA 3300 drive unit; and (b) MSA 3300 drive unit with cover removed to expose drive electronics [19].

\section{Future Vision and Technical Challenges}

\section{A. Long-Term Vision for Integrated Motor Drives}

The review of key milestones in the development of integrated motor drives presented in the preceding two sections has highlighted the impressive progress that has been made during the past 60 years toward increasing the degree of physical integration of electric machines and their drive electronics. The IMD examples that have been highlighted also demonstrate the major positive impact that this technology is already having on a wide variety of applications that range from hand dryers to electric vehicles. For engineers and technologists working in this field, this look backwards in time serves as inspiration for looking forward and asking where IMD technology and commercial development are going next, what future IMDs will look like, and what performance they will be capable of delivering compared to today's IMDs. In other words, is it possible to define a coherent future vision for integrated motor drives that can be used to guide future research and development efforts in this field?

Having viewed the landscape of progress achieved during past generations of IMDs leading up to the present, the highest level of long-term vision defining the expected external appearance and functionality of future integrated motor drives becomes rather apparent. In some sense, this vision is anti-climactic since it predicts that future IMDs will look like the motors of today; without any visible motor drive because it has been absorbed into the motor enclosure (Fig. 14). That is, the vision depends critically on the expected continuation of existing trends towards shrinkage of the volume and mass of the drive electronics. Taken to its conclusion, this trend leads to the complete embedding of the drive electronics inside the machine's enclosure without the need for any increases in the key dimensions of the enclosure. As a result, future IMDs will look like today's motors, with the drive electronics hidden from view somewhere inside the motor enclosure. The exact location of the integrated drive electronics is yet to be determined; it could be in the space currently occupied by the conventional machine's terminal box as suggested in Fig. 14, but it could be in other parts of the machine such as the end bells or stator frame.

The appeal of this future IMD vision is that the key external dimensions, mass, and volume of the motor will change very little from today's motors, but the performance and functionality of the motor will be critically transformed with speed, torque, and/or rotor position control conveniently available at the fingertips (literally) of the users. As indicated in Fig. 14, all of the communications between the user and IMD controls will be accomplished either wirelessly or via the power lines in order to avoid the need for any new signal-level control wiring between the user and the IMD. The user will be able to issue commands and monitor perfor- 


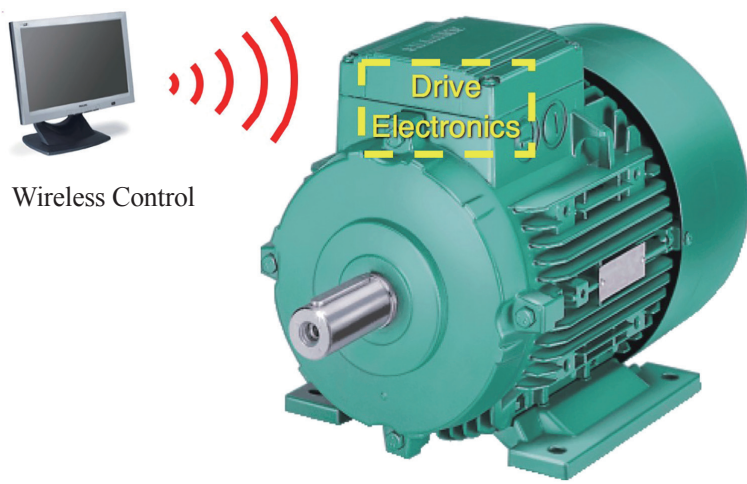

Fig. 14. Future vision of integrated motor drives with embedded power electronics.

mance (including diagnostics) using either a control console, a desktop computer, or a smart phone to provide maximum flexibility.

As the drive electronics progressively "disappears" inside the motor enclosure over time and these IMDs become more widely adopted as the baseline norm in many applications, casual users of these "smart" motors will become increasingly unaware of even the existence of the drive electronics. This is the typical and expected fate of any truly embedded technology that becomes so widely adopted yet invisible that, ironically, it becomes increasingly taken for granted by IMD purchasers and users. It will mark one of the ultimate successes of IMD technology when that happens.

\section{B. Key Technical Challenges}

Having defined the ambitious long-term vision for integrated motor drives in the preceding section, the next logical step for IMD developers and technologists is to identify the key technical challenges that must be overcome in order to achieve this vision. Here again, consideration of the past history of IMD development milestones presented in Section II and III is instructive for sharpening the focus on the most significant technology barriers that are obstructing future progress. The key technical challenges that emerge from this review, not necessarily in prioritized order which is heavily influenced by application details, are:

- Reductions in power electronics cost: Broad adoption of IMD technology in commercial, industrial, residential, and transportation applications depends on advances in power electronics technology that will lead to major cost reductions for integrated power electronics. Materials, manufacturing processes, standardization, and modularization are all expected to be major factors in accomplishing these cost reductions.

- Overcoming maximum temperature limitations of power electronics: Technology must emerge that will make it possible for power electronics to withstand the dual thermal threats imposed by placing the power electronics in close proximity to electric machines that can typically operate with hot spot temperatures of $180{ }^{\circ} \mathrm{C}$ or higher, while simultaneously packaging the power electronics within progressively smaller volumes that aggravate the heat extraction challenges. This challenge can be dissected into three sub-challenges, as follows:

o Development of higher efficiency power electronics: Reducing the losses generated by the power electronics represents a highly desirable objective for reducing both the peak temperatures and the IMD energy usage.

o Development of improved thermal management techniques: More effective heat transfer techniques for conducting the heat losses away from the IMD drive electronics and the machine can play a major role in reducing the peak temperatures in the power electronics.

o Development of higher-temperature power electronics: Development of power electronics that can reliably tolerate extended operation with junction temperatures of $200{ }^{\circ} \mathrm{C}$ or higher would represent a powerful asset for overcoming the high-temperature limitations imposed by today's silicon power devices and associated packaging.

- Major improvements in power electronics reliability: For IMDs to achieve their full potential, the integrated power electronics must be able to achieve reliability levels that match or exceed that of the electric machine in which it is embedded, despite the hostile environment it experiences. Two of the most demanding aspects of this environment are highlighted here:

o Large repeated temperature excursions: The power electronics must be able to withstand very high numbers of large temperature excursions that create tremendous stresses at the interfaces between materials with different thermal expansion coefficients in the power semiconductor modules and other critical electrical connection nodes in the power electronics.

o High vibration: In addition, the power electronics must be able to tolerate long periods of exposure to mechanical vibration caused by the motor and its connected load. Here again, the risks of vibration exposure and damage will tend to be aggravated by embedding the power electronics inside the machine enclosure unless aggressive steps are taken to ruggedize the power electronics as well as to develop vibration absorbers that significantly attenuate the vibration it experiences.

The following section of this paper highlights promising technology developments in different components and subassemblies of the IMD and its drive electronics that raise hope for successfully addressing these technical challenges.

\section{IMD Technology DeVelopments}

\section{A. Wide-Bandgap Power Semiconductors}

One of the most far-reaching and promising technologies now under development in the field of power electronics is 
wide bandgap power semiconductors using either silicon carbide $(\mathrm{SiC})$ or gallium nitride $(\mathrm{GaN})$ in place of silicon. Although the impact of WBG power semiconductor technology will not be equally significant in all application areas, it holds potential to be a game-changer that will heavily influence the future of integrated motor drives for reasons discussed below.

\section{1) $\mathrm{SiC}$ and GaN vs. Silicon Characteristics}

While the idea of replacing silicon with silicon carbide in power electronics dates back to the 1950 s, commercial development of WBG power semiconductors did not gain significant momentum until the 1990s [21]. Key motivations for using WBG materials instead of conventional silicon in power semiconductors are opportunities for significant advantages in the areas of operating temperature, efficiency, and switching frequencies. There are a number of review papers available comparing the device-level [21][22], circuit-level [23][24] and system-level [25][26] performance capabilities of WBG and Si devices. The important material characteristics influencing IMD performance are summarized in TABLE I.

As a result of their higher energy bandgap, the WBG devices can have lower leakage current at elevated temperatures, helping to raise the temperature limit of devices made with these materials. The higher breakdown electric field means that WBG devices can be designed to have much thinner drift layers and/or higher doping concentration than silicon devices. Consequently, WBG devices can have much lower on-state resistance than silicon devices with the same voltage ratings. Theoretically, the on-resistance of $\mathrm{SiC}$ devices can be 300x less than Si devices with the same voltage rating [27]. TABLE I also shows that $4 \mathrm{H}-\mathrm{SiC}$ has almost 3 times higher thermal conductivity than $\mathrm{Si}$, which is very beneficial for dissipating heat, making it possible to simplify the thermal management requirements.

Entries in TABLE I also show that the thermal conductivity of $\mathrm{GaN}$ on $\mathrm{Si}$ substrate is more than 3x lower than that of $4 \mathrm{H}-\mathrm{SiC}$. This ratio is so high because it is currently difficult to form high-quality defect-free GaN layers, and these defects result in the reduction of thermal conductivity [28]. Several combined factors enable faster switching of WBG devices including higher saturated electron drift velocity and smaller drift distance for the same blocking voltages. Due to the faster rise and fall times, the switching loss of WBG devices is lower than that of Si power switches, making much higher switching frequencies possible in most cases. Moreover, due to smaller chip dimensions of WBG devices, the gate-to-source capacitance is much smaller than for $\mathrm{Si}$ devices, enabling further improvements in the switching frequency [29][30]. The implications of this higher switching frequency on power converter performance are discussed in the next sub-section.

\section{2) Impact of Higher Switching Frequency on Power Con- verter Mass and Volume}

In addition to the size reduction of the WBG devices themselves, implementation of these switches in power converters that can operate at much faster switching frequencies opens opportunities for significant size and mass reduction of the resulting power converters, one of the major objectives for future IMD technology. Illustrating this principle, Fig. 15 shows that the volume of an inverter output $L C$ filter can be reduced by more than $2: 1$ when $\mathrm{SiC}$ power switches are used to increase the switching frequency from 20 to $50 \mathrm{kHz}$ [24]. A project supported by the US Department of Energy demonstrated the potential for achieving high power density and efficiency metrics using SiC and GaN power semiconductors, although the focus of that particular project was not on high PWM switching frequencies [31][32]. Mitsubishi Electric has announced development of a SiC-based prototype EV traction drive that achieves a power density of $86 \mathrm{kVA} / \mathrm{L}$ for a two-motor hybrid $\mathrm{EV}$, more than 5 times the power density for comparable Si-based power converters now in production [33]. Although promising, few technical details are available at this time that explain how this was achieved.

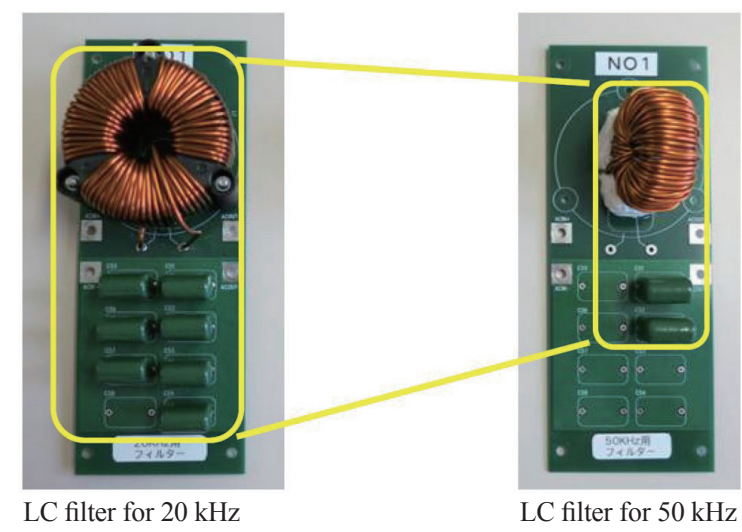

Fig. 15. Comparison illustrating reduction of LC filter footprint made possible by raising the PWM switching frequency from 20 to $50 \mathrm{kHz}$ [24].

Achieving such dramatic size reductions via switching

TABLE I

Key Material Properties of Si, 4H-SiC and GaN on Si Substrate

\begin{tabular}{ccccc}
\hline \hline Parameter & Bandgap(eV) & Break down elect field. (MV/cm) & Thermal cond. (W/mk) & Sat. electron velocity $\left(10^{6} \mathrm{~cm} / \mathrm{s}\right)$ \\
\hline $\mathrm{Si}$ & 1.1 & 0.25 & 150 & 10 \\
4H-SiC & 3.2 & 2.2 & 490 & 20 \\
GaN on Si Substratc & 3.4 & 2.0 & 130 & 22 \\
\hline \hline
\end{tabular}


frequency increases with a complete power converter is not a simple task. More specifically, the mass/volume reduction of passive components is not a simple inverse-linear relationship with switching frequency when all factors are considered. The dc-link capacitor in a voltage-source inverter (VSI) is a good example. Based only on a capacitance calculation, the required capacitance mass and volume decreases inversely with the frequency (i.e., 1/f). However, in practice, the capacitor's rms current requirements eventually dominate the sizing of these capacitors, changing the results significantly.

As shown in Fig. 16 [28], when the switching frequency is raised higher than a threshold frequency value, the capacitor volume no longer reduces because meeting the rms current requirement prevents it. The curves for three types of capacitors shown in Fig. 16 reveal that this threshold frequency value is lowest for electrolytic capacitors, and significantly higher for both film and ceramic capacitors, reflecting differences in their current-handling capabilities. As discussed later in Section V.C, efforts to achieve major size and volume reductions using WBG switches can benefit significantly from consideration of alternative power converter topologies.

\section{3) Impact of Higher Junction Temperatures on Power Con- verter Mass and Volume}

As noted earlier in this section, WBG devices can operate at much higher junction temperatures than silicon devices. Complementing this feature is the fact that WBG power switches (particularly $\mathrm{SiC}$ at the time) exhibit only modest increases in on-state resistance and switching losses as the temperature rises. As a result, the total losses of $\mathrm{SiC}$ devices devices are relatively insensitive to temperature increases. These appealing features open opportunities to reduce the thermal management requirements for the power converter if all of the other converter components can be designed to tolerate higher temperatures.

Past studies including both simulation and experiment have demonstrated that $\mathrm{SiC}$ power switches make it possible to reduce the mass of cooling systems for an EV drivetrain [34]. The thermal management systems in production hybrid EVs using conventional silicon-based power converter now often employ two cooling loops, one for the internal combustion engine with $105{ }^{\circ} \mathrm{C}$ coolant, and a second loop with a lower temperature coolant at $80{ }^{\circ} \mathrm{C}$. Due to the high tem-

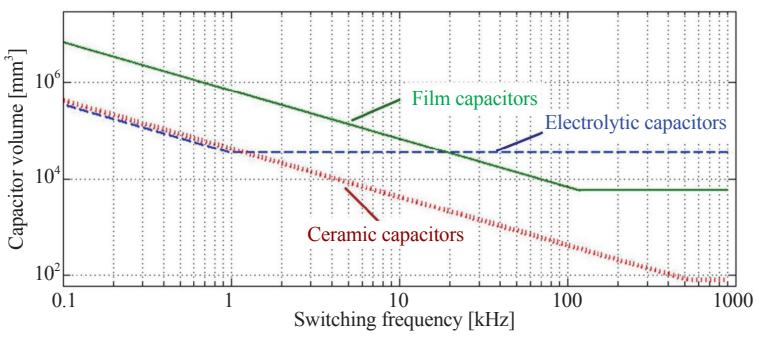

Fig. 16. Calculated plots of VSI dc-link capacitor volume vs. switching frequency for three types of capacitors [28]. perature capability of $\mathrm{SiC}$, it becomes technically feasible to eliminate this lower temperature cooling loop, resulting in a significant volume reduction for the inverter combined with its thermal management system [35]. A separate study for the powertrain of a battery $\mathrm{EV}$ using $\mathrm{SiC}$ indicates that, with the same thermal management conditions, SiC power modules can achieve current densities that are $2.5 \mathrm{x}$ higher than for Si-based power modules [36]. Another study also predicts that a dc/dc power converter (3 to $10 \mathrm{~kW}$ ) in an EV powertrain can achieve $25 \%$ reductions in both volume and mass and eliminate the need for fan cooling by using $\mathrm{SiC}$ power devices instead of conventional silicon semiconductors [37].

Other studies have focused more directly on the opportunities provided by WBG power devices to reduce the mass and volume of the heatsinks by using WBG devices. For example, researchers calculated that the required heat sink for a $\mathrm{SiC}$-based power converter only requires a thermal resistance value of $0.11 \mathrm{~K} / \mathrm{W}$, making it possible to use either natural or forced-air convection [38]. In comparison, the heatsink for a Si-based converter with the same power rating requires a much lower thermal impedance of $0.0035 \mathrm{~K} / \mathrm{W}$, a value $>30 \mathrm{x}$ lower than for the $\mathrm{SiC}$ power converter that demands a liquid-cooled heat sink.

As noted earlier in this discussion, the full value of operation with higher junction temperatures offered by WBG power devices cannot be realized unless all of the other electronics, including the device package in which the WBG die is mounted, is designed to operate reliably in higher-temperature environments than they can today. There is a community of researchers in industry and academia who have demonstrated that it is possible to build motor drive inverters using $\mathrm{SiC}$ power switches that can operate for extended times with junction temperatures that approach or exceed $200{ }^{\circ} \mathrm{C}$ [39]. However, the commercial availability of the necessary components to manufacture high-temperature power converters at sufficiently low cost for high-volume consumer applications is highly limited. This topic will receive more attention later in this paper.

\section{B. Integrated Modular Motor Drive (IMMD)}

The heart of the future IMD vision presented in Section IV.A lies with the integration of the drive electronics inside the motor enclosure, referred to in this section as an embedded IMD. Although there are very few commercial IMDs that have adopted such an ambitious approach, there are some researchers who have explored this IMD architecture. For example, a prototype version of an induction motor drive with a matrix converter built into the machine's end bell has been reported [40]. Nevertheless, the literature associated with this aggressive class of embedded IMDs is quite limited. This section presents a summarized discussion of a particular embedded IMD concept known as the Integrated Modular Motor Drive (IMMD) [41] that illustrates some of the specific technical challenges as well as progress that has been made during recent years towards realization of key 
aspects of the embedded drive electronics architecture envisioned for future IMDs.

\section{1) Basic IMMD Concept}

The Integrated Modular Motor Drive is a concept that was first conceived in 2004 to simultaneously address technical issues associated with the embedded IMD architecture as well as modularization of the machine's stator and inverter. As illustrated in Fig. 17, the IMMD divides both the power converter and the machine stator into individual phase segments. An individual stator core arc segment with its concentrated winding is physically integrated with a single-phase inverter module and its own dedicated controller to form an integrated pole-drive unit. A number of these identical pole-drive units (equal to the number of concentrated stator windings in the machine) are then interlocked and interconnected to form an annular stator assembly that comprises both the IMD's machine stator assembly and the motor drive inverter.

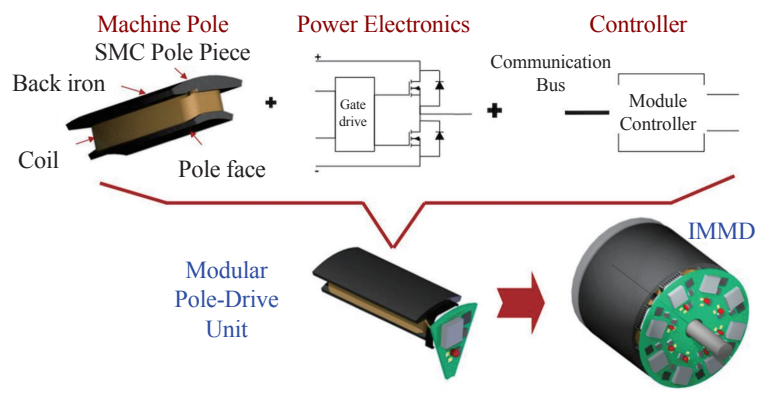

Fig. 17. Basic concept of Integrated Modular Motor Drive (IMMD) [46].

The modularity of this IMMD architecture was introduced with the dual objectives of improving its manufacturability as well as its potential for achieving high fault tolerance [41]. Although these features raise their own set of challenging technical issues, they are not the focus of this discussion. Instead, attention is focused on progress made towards miniaturizing the size of the power converter in order to make it compatible with being embedded inside the machine enclosure. This is accomplished by highlighting the progress that has been made in this direction during two successive generations of prototype IMMD units. More information about preceding technical work on the IMMD concept that set the stage for the two prototype units highlighted in this paper is available in the literature [42]-[45].

\section{2) Second Generation IMMD with Silicon-Based Power Electronics (2014)}

Work on developing this prototype IMMD began with a systematic evaluation of machine topologies suitable for a compact IMMD with high power density and efficiency [44]. This investigation determined that a 6-phase, 10-pole PM machine topology was the best candidate for this project. A complete IMMD demonstrator unit shown in Fig. 18(c) consisting of a modular 6-phase, 10-pole, $10 \mathrm{~kW}$ (continuous)

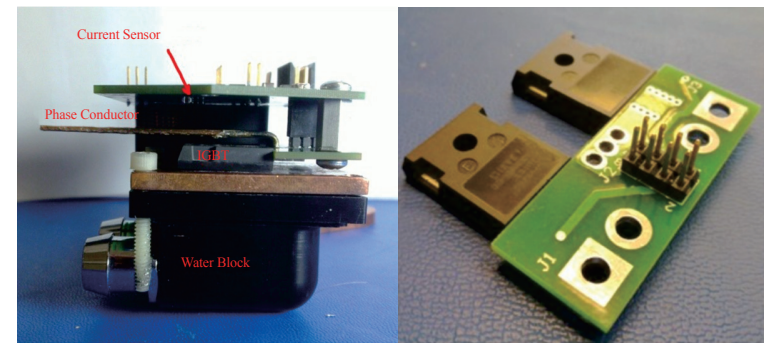

(a)

(b)

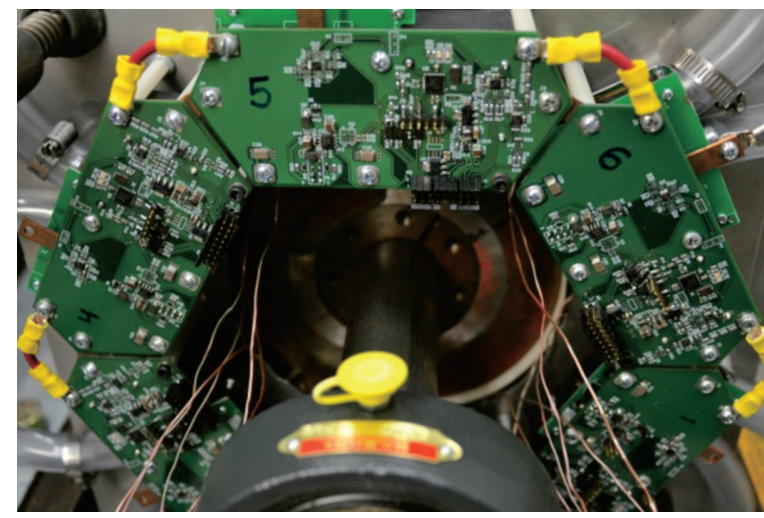

(c)

Fig. 18. $2^{\text {nd }}$ generation Si-based IMMD demonstrator unit: (a) Pole-drive unit side view [46]; (b) Module Si IGBT power stage in phase-leg topology; (c) 6 pole-drive electronic modules mounted in IMMD configuration adjacent to a 6-phase modular PM machine

surface PM machine with six modular pole-drive electronics modules was designed, constructed, and tested, as shown in Fig. 18(a) [46][47]. This was the first IMMD prototype unit that included a dedicated controller in each module.

The IMMD was designed to deliver a maximum peak power of $18 \mathrm{~kW}$. Each pole-drive unit incorporates a halfbridge inverter phase-leg operating from a nominal $325 \mathrm{Vdc}$ bus using two discrete $600 \mathrm{~V}$ IGBTs in TO-247 packages as shown in Fig. 18(b). In addition to the two IGBTs, the power stage includes an RTC temperature sensor, gate connections, and a mounting terminal for the machine phase busbar. Cooling for each phase-leg module is accomplished using an off-the-shelf copper pin-fin waterblock designed for graphics card cooling. As shown in Fig 18(c), the power module is mounted in direct contact with the waterblock to minimize the thermal resistance. High-bandwidth $(\sim 10 \mathrm{kHz})$ current sensing is provided by a linear Hall effect sensor mounted to the bottom of the control board as indicated in this same side-view image.

\section{3) Third Generation IMMD with GaN-Based Power Elec- tronics (2016)}

The third-generation IMMD prototype units takes advantage of the benefits that $\mathrm{GaN}$ power devices provide for reducing the inverter mass and volume including higher switching frequency and lower conduction losses [28][48]. Like the $2^{\text {nd }}$ generation IMMD discussed above, this proto- 
type IMMD unit also uses a 6-phase ac machine, although in this case it is an induction machine. Another difference between the two generations is that the $3^{\text {rd }}$ generation configures the 6 pole-drive units into two 3-phase full-bridge inverters that are in series, rather than in parallel (Fig. 19(a)). This makes it possible to use GaN devices with lower voltage ratings, which reduces the device's on-state resistance and conduction losses. This lower bus voltage for each 3-phase inverter also makes it easier to use small film or ceramic capacitors instead of electrolytic units. This is important since the commonly-used electrolytic capacitors often take up more than $30 \%$ of the conventional inverter's total volume, making it a limiting factor for increasing the IMMD's power density. Increasing the PWM switching frequency from $20 \mathrm{kHz}$ in the $2^{\text {nd }}$ generation IMMD to 100 $\mathrm{kHz}$ in the $3^{\text {rd }}$ generation unit also plays a valuable role in shrinking the size of the power electronics.

Since the power rating of the induction machine for the $3^{\text {rd }}$ generation IMMD prototype unit is only $1.2 \mathrm{~kW}$, much lower than the $10 \mathrm{~kW}$ rating of the $2^{\text {nd }}$ generation PM machine, it is difficult to make direct quantitative comparisons between the two units. However, Fig. 19(b) provide some helpful insight into the size reduction benefits provided by the change from silicon to GaN power switches. This figure compare the size of a preliminary version of the inverter using Si MOSFETs in a 3-phase inverter module switching at $10 \mathrm{kHz}$ to the final version of the 3-phase inverter consisting of 3 single-phase modules using GaN devices switching at $100 \mathrm{kHz}$ (Fig. 19(b)). The significant reduction in the inverter area is very apparent.

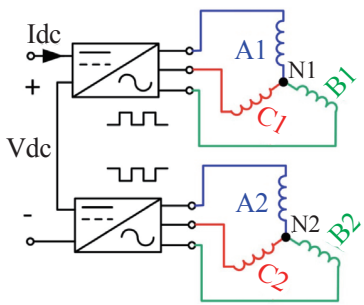

(a)

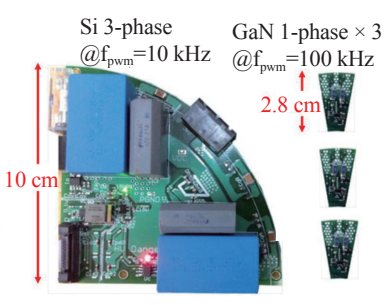

(b)
Fig. 19. $3^{\text {rd }}$ generation IMMD: (a) Electrical configuration of $1.2 \mathrm{~kW}$ drive using two 3-phase full-bridge inverters in series; (b) Comparison of Si vs. GaN implementations of $0.6 \mathrm{~kW}$ 3-phase inverter [28].

Two views of the assembled $3^{\text {rd }}$ generation IMMD prototype unit are provided in Fig. 20. The front view in Fig. 20(a) shows the two 3-phase inverters on the left- and rightsides of the endplate, and the drive controller is mounted in the top quadrant. The $12 \mathrm{GaN}$ switches are mounted in thermal contact with the outer surface of the aluminum endbell which is sufficient to serve as the inverter's heatsink without forced-air cooling. The side view of the IMMD unit provided in Fig. 20(b) shows that the thickness of the IMMD drive electronics is only $1.3 \mathrm{~cm}$. Although this drive electronics unit is mounted on the external surface of the motor's end bell for convenient viewing without disassembly, the drive electronics has been sufficiently miniaturized to be compati- ble with embedding inside the motor end bell cavity without requiring any changes in the housing dimensions. As a result, comparison of the $2^{\text {nd }}$ and $3^{\text {rd }}$ generation IMMD prototype units provides convincing evidence of the positive impact of well-designed WBG-based drive electronics on the prospects for achieving embedded drive electronics in future IMDs.

\section{WBG-Enabled Current-Source Inverters}

As discussed in Section V.A, new WBG power semiconductors fabricated using both silicon carbide $(\mathrm{SiC})$ and gallium nitride $(\mathrm{GaN})$ are becoming available that can switch more than 10 times faster than their silicon-based counterparts. There are high hopes in the research community that these new WBG power switches will ultimately deliver major benefits to applications such as IMDs that desperately need breakthroughs that will lead to smaller, lighter, and more efficient power electronics.

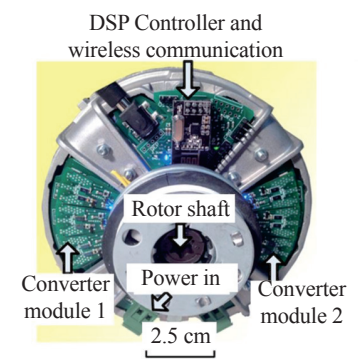

(a)

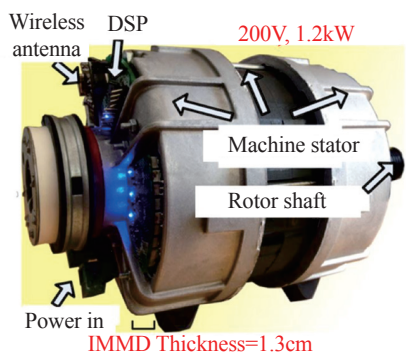

(b)
Fig. 20. $3^{\text {rd }}$ generation GaN-based 6-phase IMMD unit rated at $1.6 \mathrm{~kW}$; (a) Front view of IMMD drive electronics; (b) Side view [28].

However, when attempts are made to use these WBG devices as drop-in replacements for silicon-IGBTs in conventional voltage-source inverter (VSI) machine drive inverters with PWM switching frequencies of $100 \mathrm{kHz}$ or higher, vexing problems caused by their much higher $d v / d t$ values have emerged, including machine terminal over-voltages and significantly elevated EMI levels [49]-[51]. There are also growing indications that such fast $d v / d t$ values can lead to dynamic interations between the drive, connecting cables and the motor load that results in noticeable reduction in efficiency [52]. These problems are sufficiently difficult to solve that they have triggered interest in exploring whether other inverter topologies might offer natural advantages over VSIs when WBG power switches are introduced.

One class of inverter topologies that deserves special attention as a WBG-friendly alternative to the familiar VSI inverter is the PWM current-source inverter (CSI). The PWM-CSI topology has received some past attention from researchers [53], but the topology has been largely ignored by industry because it is not easily compatible with silicon-based power switches. The basic power circuits of both VSI and CSI topologies are provided in Fig. 21 for easy comparison. The replacement of the dc-link capacitor in the VSI with a dc link inductor is one of the three biggest differences. Secondly, the CSI needs filter capacitors at the invert- 


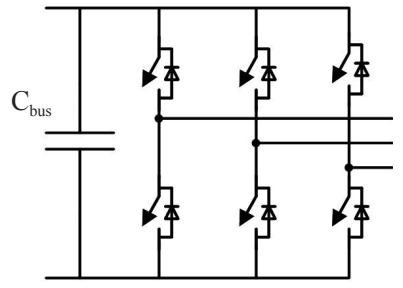

(a)

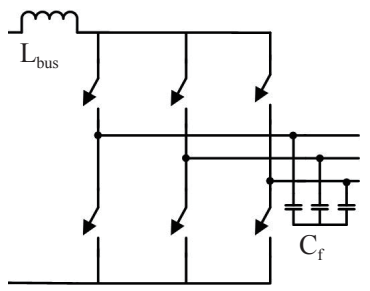

(b)
Fig. 21. Basic inverter topologies of 3-phase inverters; (a) VSI; (b) CSI.

er output terminals to make the basic CSI compatible with inductive loads, a feature of most motors. Finally, the presence of the anti-parallel diodes in the VSI and their absence in the CSI reflects the fact that the CSI needs power switches that can block reverse voltages, unlike the VSI. Fortunately, WBG power switches offer some interesting possibilities for realizing reverse-blocking switches that are not easily achieved with silicon-based IGBTs or MOSFETs [54]-[56].

Unfortunately, space in this paper does not permit a full discussion of the potential advantages offered by the CSI inverter topology over the VSI when WBG power switches are introduced. However, some valuable insights into the nature of these advantages can be gained by comparing the terminal voltage waveforms delivered at the output terminals of the two types of inverters. Fig. 22 shows simulated terminal voltage waveforms for a VSI and CSI when the WBG power devices are switching at $200 \mathrm{kHz}$, more than 10 times the typical PWM switching frequency for silicon power switches. The VSI output voltage waveforms swings between the positive and negative bus voltages at the PWM switching frequency, while the corresponding output waveforms for the CSI are much smoother because of the presence of the output filter capacitors acting together with the dc link bus inductor to filter out much of the harmonic content. Adopting a high PWM switching frequency of $100 \mathrm{kHz}$ or higher plays a key role in reducing the mass and volume of the dc link inductor and the output filter capacitors which are in value ranges that make ceramic capacitor excellent choices.

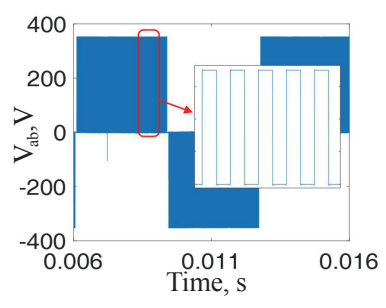

(a)

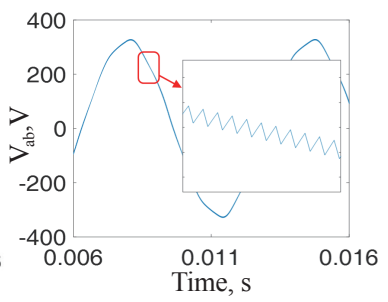

(b)
Fig. 22. Simulated output voltage waveforms for two inverters using WBG switches at $f_{p w m}=200 \mathrm{kHz}$ : (a) VSI (without output filter); and (b) CSI.

The sinusoidal output voltage waveforms delivered by the CSI pose much less risk of generating dangerous over-voltages at the motor terminals or unacceptable common-mode EMI levels compared to the harmonic-rich VSI output voltage waveforms. While it is true that the VSI voltage waveforms with their incredibly fast voltage transition would be far less problematic if a 3-phase $L C$ filter is added to the inverters output terminals [49][57], the need to add a filter inductor in each phase in addition to the filter capacitances puts the VSI at a mass and volume disadvantage compared to the CSI when the filters are added to the VSI.

In addition to the attractive features noted above in the areas of mass, volume, EMI, resonant over-voltages, and efficiency, there are two more potential advantages for future IMD designs that are worth noting. First, the CSI is an excellent candidate for high-temperature operation compared a VSI. More specifically, the major passive components in the CSI are the dc link inductor and the ceramic capacitors used for the output filter capacitors, both of which are compatible with operation at temperatures $>200{ }^{\circ} \mathrm{C}$. In contrast, the dc link capacitor in the VSI is typically implemented using either electrolytic or film capacitors which are limited to maximum temperatures of $125^{\circ} \mathrm{C}$ and $170^{\circ} \mathrm{C}$, respectively. The second notable advantage of the CSI when used with a PM synchronous machine is that the absence of anti-parallel diodes across the inverter switches makes the CSI motor drive less vulnerable to highly dangerous short-circuit faults in one of the inverter switches, increasing its fault tolerance [58].

It is acknowledged that preceding discussion in this section has relied on brief qualitative arguments without quantitative evidence that is being provided in other technical papers, some of which are already published [59] and others that are in preparation. However, the key larger point being made is that treating WBG switches as drop-in replacements for silicon IGBTs or MOSFETs may not yield the best solution when there are good reasons to significantly raise the switching frequency or operating temperature. Applying these radically new WBG switches with terminal characteristics that are significantly different from those of the current generation of silicon switches calls for a serious re-evaluation of the most compatible power converter topologies to take full advantage of these new switch features and characteristics, and the CSI is just one example. If successful, future IMD designs will benefit significantly from the advantages made possible by using WBG switches in the most suibtable converter topologies.

\section{Drive Electronics Technology Advances and Future Directions}

As important as the emerging WBG power device technology may be to achieve the long-term future vision of integrated motor drives, there is an equally urgent need for technology breakthroughs in many other aspects of the drive electronics in order to achieve the demanding objectives for power density and reliability/robustness in hostile thermal and vibration environments at an affordable cost. This section is devoted to providing a brief summary of some promising new technology developments that have been reported as well as remaining unmet needs. This discussion is broken into two major topics. The first topic addresses new technologies that primarily influence the long-term reliability and robustness of the IMD's drive electronics, and the second 
topic focuses on technologies associated with achieving the goal of embedding the power electronics inside the motor enclosure.

\section{1) Power Electronics Reliability/Robustness Technologies}

Advanced Power Semiconductor Packaging: When working to take advantage of the extremely high switching frequencies and high junction operating temperatures of WBG power devices, it quickly becomes apparent that these advantages lose nearly all of their value unless the power semiconductor packages used to mount the WBG die and the associated power module packaging are completely compatible with these features. Unfortunately, the large majority of power device and module packages widely used today for silicon power devices are painfully deficient for use with WBG devices intended for use at either high switching frequencies $(>100 \mathrm{kHz})$ or high junction temperatures $\left(>175^{\circ} \mathrm{C}\right)$.

Focusing first on the issue of high-temperature operation and the related issue of thermal cycling with large temperature differences, there are a significant number of promising technologies that are either in development or already being introduced into the marketplace. Considering the typical power module cross-section layout illustrated in Fig. 23, the new technologies can be divided among those associated with making electrical connections to the die, and a second category associated with mounting the die on the substrate. TABLE II, which is not exhaustive, identifies a number of the new technologies that are designed to increase the power device's ability to operate at higher temperatures and withstand high thermal cycling.

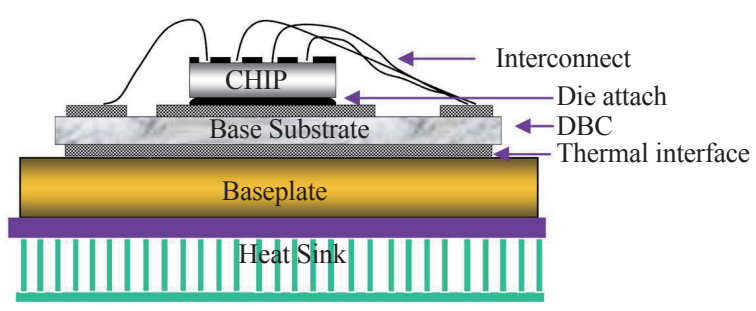

Fig. 23. Cross-section of conventional power module construction.

TABLE II

Advanced Technologies for Power Module Consruction

\begin{tabular}{|c|c|c|}
\hline Category & Solution Type & Representative Technologies \\
\hline \multirow{2}{*}{$\begin{array}{l}\text { Die } \\
\text { Interconnect } \\
\text { and Joining }\end{array}$} & Material & $\begin{array}{l}\text { Sintered silver [60], MoCu [36], } \\
\text { AlSiC [62] }\end{array}$ \\
\hline & Structure & $\begin{array}{l}\text { Ribbon bonding [63], copper pin [64], sol- } \\
\text { der ball [65], SKiN [66], Planar intercon- } \\
\text { nect [67], Pressure contact [68] }\end{array}$ \\
\hline \multirow{3}{*}{$\begin{array}{l}\text { Substrate } \\
\text { Construction }\end{array}$} & \multirow{2}{*}{ Material } & $\begin{array}{ll}\text { Insulation layer } & \mathrm{A} 12 \mathrm{O} 3[61], \mathrm{AIN}[69] \\
& \mathrm{LTCC}[70]\end{array}$ \\
\hline & & Conducting layer $\quad \mathrm{DBA}[60]$ \\
\hline & Structure & Stepped edge [61] \\
\hline
\end{tabular}

Recognizing the fatigue limitations of conventional wire bonds for electrical connections on the top-side of the power device die, there has been significant research and market introductions of alternative technologies that eliminate the wire bonds, often in favor of planar interconnect techniques. For example, the SKiN connection introduced by Semikron in 2011 offers a large thermal cycling reliability improvement compared to conventional wire-bond connections [66].

To minimize mechanical fatigue during high thermal cycling, sintered silver can be used as the die attach method in order to take advantage of its ability to absorb the repeated mechanical stresses associated with mismatches in the Coefficient of Thermal Expansion (CTE) between the die and substrate materials [60]. Some other materials (e.g., $\mathrm{MoCu}$ and $\mathrm{AlSiC}$ ) offer a relatively close CTE match with $\mathrm{SiC}$ which helps to achieve more reliable die attachment. Another approach for improving the fatigue life of the die attach technique is based on modifying the die's geometric structure to provide better mechanical strength. As shown in [61], a die with stepped edges combined with a $\mathrm{Al} 2 \mathrm{O} 3$ ceramic substrate exhibits more than 40x the thermal life cycle capability of normal die attachment to AIN direct-bond copper (DBC) substrates.

High-Temperature Passive Components and Controllers: In addition to improving the power module's high-temperature operation capabilities, other components of the IMD drive electronics including passive devices (capacitors and inductors) and control electronics also determine the maximum temperature limits of the unit.

Currently, high-temperature electronic components for motor drives is a niche market for special applications such as down-hole drilling and aerospace that demand it and can afford the significant cost premium. However, there is increasing interest in attaining higher-temperature operation for motor drives in other fields with larger markets such as automotive accessories and EV traction drives because of opportunities to save money by reducing/simplifying the cooling requirements [71]. New types of film capacitors are

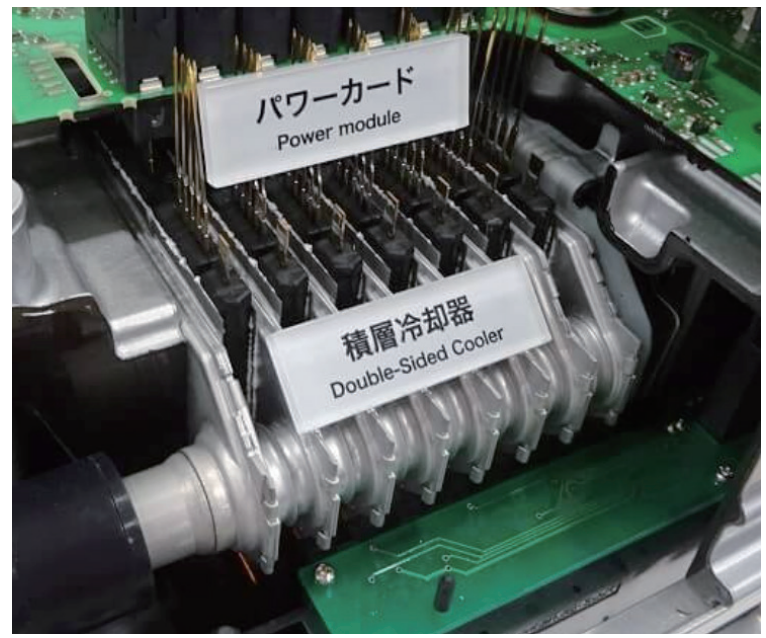

Fig. 24. Toyota EV traction inverter with double-sided cooling of power modules [79] used in Prius models. 
being introduced that raise their maximum operating temperatures to $175^{\circ} \mathrm{C}$ [72]. While some ceramic capacitors are already capable of operation at temperatures higher than $200{ }^{\circ} \mathrm{C}$, new capacitor technologies based on alternative materials such as silicon [73] and glass [74] have been reported in the literature that can operate at temperatures greater than $250{ }^{\circ} \mathrm{C}$ and $200{ }^{\circ} \mathrm{C}$, respectively. Inductor cores using powder as the core material are available that permit safe operation at temperatures up to $200{ }^{\circ} \mathrm{C}$.

In addition to these passive components, integrated circuit technology is available that is compatible with high-temperature operation. For example, micro-controllers are already commercially available (albeit at a significant cost premium) with temperature ratings as high as $150{ }^{\circ} \mathrm{C}$ [75]. Turning attention back to the power electronics, researchers have successfully demonstrated high-temperature operation of a silicon-on-insulator-based gate drive operating in an ambient temperature as high as $200{ }^{\circ} \mathrm{C}$ [39].

Advanced Thermal Management: Taking advantage of continue advancement in additive manufacturing (3D printing) technology, complex shapes that are difficult or impossible to manufacture using traditional methods can be easily manufactured in a quick and cost-effective manner. For example, researchers at the UW-Madison [76] and Toyota [77] have demonstrated that they are able to build heatsinks with significantly higher thermal efficiency for both air and liquid cooling using additive manufacturing technology.

In addition to heatsinks, there has been effort to improve thermal dissipation by optimizing the thermal interface between the power devices and the heatsink. For example, there have been major research programs around the world working on reducing or eliminating the need for thermal interface materials that are designed to improve the thermal coupling between a power module's baseplate and the heatsink. One of the approaches that is already being used extensively by automotive manufacturers of EV inverters is direct substrate cooling technology [78].

In addition, Toyota was the first automotive manufacturer to introduce double-sided cooling of the power modules in the EV traction inverter for their 2008 Lexus hybrid LS600h model, and it more recently has been adopted for their hybrid Prius models (Fig. 24) [79]. Fig. 25 provides a visual summary of thermal cooling technologies adopted by various automotive manufacturers and suppliers during the past decade [80]. Other cooling methods under development for electronic assemblies with high thermal flux values include single-phase cooling, two-phase cooling, jet impingement and spray cooling, and thermoelectric cooling [81].

\section{2) Advanced Power Converter Integration and Manufactur- ing Technologies}

Conformal Power Electronics: As stated in Section IV.A, the long-term vision for integrated motor drives is to embed the drive electronics inside the motor enclosures. This is quite challenging since today's power electronics is generally predominantly two-dimensional, often using a flat printed circuit board as the skeleton for the power converter's

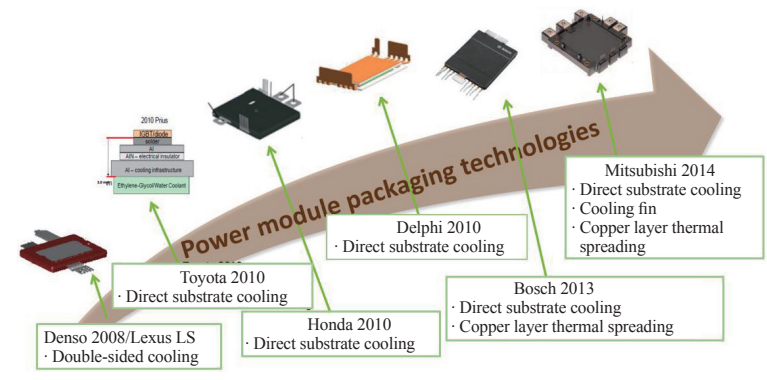

Fig. 25. Summary of advanced cooling technologies developed/adopted by automotive manufacturers and suppliers since 2008 [80].

physical design. The limitations imposed by this design and manufacturing paradigm for today's power electronics are quite restrictive when trying to convert this type of assembly into an embedded configuration that fits comfortably inside a motor enclosure with minimal modifications of the enclosure design.

One of the most promising pathways for escaping these limitations is additive manufacturing. An attractive feature of additive manufacturing is that it opens up the third dimension for the power electronic designer. This raises hope that additive manufacturing technology will eventually provide the key to developing drive electronics modules that can be conveniently designed to fit conformally within the contours of motor enclosures, such as inside the end bell assemblies. There are already some early reports of research efforts seeking to apply 3D printing technology to the fabrication of an inverter power stage, as shown in Fig. 26 [82]. However, the results presented to date suggest that this R\&D is still in a very early stage, and there is much to be done to take full advantage of the possibilities made available by additive manufacturing technology.

As noted in the preceding discussion about advanced thermal management techniques, thermally-conductive polymers are being developed that can be used in the additive manufacturing process. This is intriguing in the context of future embedded IMD designs because it suggests that there

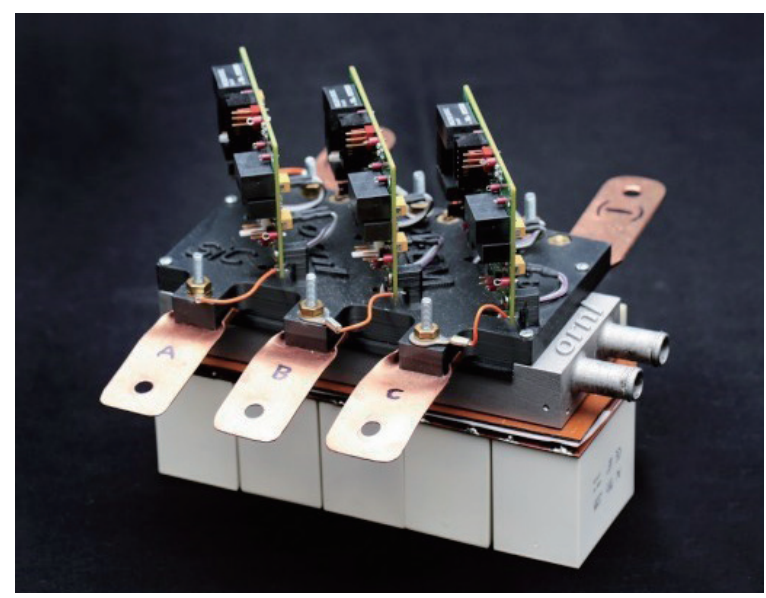

Fig. 26. Prototype $30 \mathrm{~kW}$ inverter with approx. 50\% 3-D printed components [82]. 
might be clever techniques within reach for using these thermally-conductive structural materials to enhance the transfer of heat from the power electronics into the motor housing where it can be efficiently dissipated. Much more work is necessary to determine whether such concepts will lead to cost-effective approaches for manufacturing embedded power electronics in the future.

Higher Levels of Power Electronics Integration: The electronics for today's motor drives is generally manufactured using a large number of discrete parts that are mounted and interconnected using a printed circuit board. Even the gate drives are often custom-designed for each product using discrete parts, limiting the opportunities to drive down costs by manufacturing very large numbers of standardized commodity assemblies. The idea of power electronics integration is not a new one. For example, concept of Integrated Power Electronics Modules (IPEMs) was introduced in the late 1990s, integrating both active and passive components into compact assemblies [83]. This concept was later extended to higher-power applications using the Power Electronics Building Block (PEBB) concept [84]. Only some features of these approaches have gained wide acceptance by industry to date.

In 2002, International Rectifier introduced fully-integrated Intelligent Power Modules (IPMs) using silicon technology for special motor drive market segments including servo drives that integrated all of the power electronics including the inverter power state, gate drives, and all of the drive control electronics. Although these power modules provided impressive performance capabilities within a single EconoPack2 power module package, they did not succeed in the marketplace because of the economic challenges associated with gaining a sufficiently large production base to drive down the costs.

In summary, a combination of technology and economic hurdles has limited the development of a robust market for integrated motor drive electronics modules. Efforts are now under way to explore the opportunities that planar GaN technology may open for building inverters-on-a-chip using a monolithic integrated power electronics architecture [85]. Here again, time and patience will be required to determine how power electronics integration technology can play a role in driving down the cost of future IMDs with embedded drive electronics.

Power Electronics Modularization for Improved Manufacturability: As noted earlier in this paper when introducing the Integrated Modular Motor Drive (IMMD) technology in Section V.C, one of the motivations for the IMMD concept is to develop phase-drive units that include modularized power converters as a path to simplify manufacturing and drive down production costs. While there is significant evidence that modularization of power converters can work very effectively for static power supplies in applications such as data centers that require very large numbers of identical supplies, the evidence to prove the advantages of modularization in motor drives is much weaker to date. Depending on progress with the two preceding power electronics integration concepts in this section, it may be that drive electronics modularization will play a more important role in the future, but, for now, this topic remains primarily in the research realm.

\section{ConClusions}

As indicated by its title, this paper has provided readers a summarized review of the past, present, and future of integrated motor drives. By highlighting key milestones in the history of IMDs stretching back more than 55 years, both the boldly innovative spirit of past generations of engineers who developed these landmark IMDs as well as the consistent progress towards higher levels of drive electronics integration and compactness have been very apparent. Taken together, this history points to a bright future for integrated motor drives as the drive electronics moves closer each year to complete absorption into the motor enclosure.

Of course, this ultimate objective cannot be achieved without multiple technology breakthroughs that will be required to enable such major progress. As discussed in this paper, there is reason for optimism that the necessary technology breakthroughs will appear and mature, leading to fulfillment of the vision of complete physical absorption that was noted above. Rapid development in the critical field of wide bandgap power semiconductors will be one of the most important technology contributors to achieving this future vision, but certainly not the only one.

A summary of key observations and conclusions to be drawn from this paper includes the following:

- Integrated motor drive technology has already left an indelible mark on the history of adjustable-speed drives as well as today's commercial motor drive offerings

- IMD technology will become significantly more powerful during coming years, culminating eventually in drive electronics that will be completely embedded in motor drive enclosures with little negative impact on the motor's mass or volume.

- Success in achieving this ambitious IMD vision will depend on the availability of future drive electronics that incorporates:

o New materials such as wide bandgap semiconductors and carbon nanotubes that will make it possible to significantly reduce the losses in the drive electronics and then remove the heat more effectively.

o New integration techniques that will make it possible and inexpensive to manufacture the drive electronics directly into the machine housing, escaping today's limitation that dictate primarily two-dimensional drive electronics.

o New concepts for achieving robustness/reliability objectives that will make it possible for all of the components in the drive electronics to operate for extended time periods in hostile thermal and vibration environments, accompanied by advanced diagnostics 
and fault tolerance.

- The rate of progress towards achieving the long-term IMD vision depends heavily on taking a strongly multi-disciplinary, multi-physics approach to addressing the difficult technical challenges that must be overcome in order to achieve the vision.

The last point in this summary represents a serious challenge that calls for action by both industry and academia to nurture a new breed of engineers that is specially educated and trained to attack the most complicated cross-disciplinary technical problems that are retarding the future growth of IMD technology. Despite the tremendous progress that has been accomplished to date, achieving the full potential of integrated motor technology depends on a collective commitment to breaching the barriers between all of the engineering disciplines including electrical, mechanical, and materials in order to reach the ultimate limits of motor/drive integration. The rewards that will accompany success make overcoming these challenges well worth the effort.

\section{REFERENCES}

[1] M. Bradfield, "Thermal design challenges in automotive alternator power electronics," Electronic Cooling, vol. 8, no. 2, May 1, 2002.

[2] "Denso produces 100 millionth SC alternator," Denso Corp., Press Release, Jun. 14, 2012.

[3] C. Mohalley, "Electronically commutated motors, Part 1: history and overview of ECMs," Service Application Manual, Refrigeration Service Engineers Society, Chapter 650-003, Sec. 6A, 2010.

[4] Presenting the GE ECM2.3 Series Motors, GE Industrial Systems, GET-8068, 2000.

[5] H. O. Pederson, "SQ - submersible pum with integrated permanent magnet motor drive," in Energy Efficiency Improvements in Electronic Motor and Drives, P. Bertoldi et al, Ed. Berlin: Springer Verlag, 1997.

[6] Turbocor compressor technology for liquid chiller applications, Danfoss Turbocor Compressors Inc.,[Online].Available: http://www. turbocor.com/literature/pdfs/product_literature/General_Presentation. pdf .

[7] “VLT DriveMotor FCM 300," Factsheet, Danfoss VLT Drives, 2014.

[8] "MOVIMOT Gearmotors," Catalog, SEW Eurodrive, Sept. 2016.

[9] "IndraDrive Mi: Cabinet-free drive technology for maximum flexibility and efficiency,"Brochure, Rexroth Bosch Group, Nov. 2016.

[10] D. Grabham.(1993,February).How Dyson gets air to move at 430 mph. Techradar, [Online].Available: http://www.techradar.com/news/ world-of-tech/how-dyson-gets-air-to-move-at-430mph-1129477 .

[11] “2005 Escape Hybrid ," Ford Motor Corp., presentation at FutureTruck 2004 Competition, June 16, 2004.

[12] H. Hisada et al, "Aisin AW new full hybrid transmission for FWD vehicles," SAE International, Apr. 11, 2005.

[13] H. Shimizu et al, "Development of an integrated electrified powertrain for a newly developed electric vehicle," SAE International, Ap. 8, 2013.

[14] B. McNamara.(2013,August).Tesla S test drive. bmcnamara.com, [Online].Available: http://www.bmcnamara.com/tesla-model-s-testdrive/.

[15] (2015, September). In a Tesla Model S, there is no IGBT packaging trick, PntPower.com, [Online]. Available:https://www.pntpower.com/ on-tesla-electric-vehicles-semiconductor-packaging/.

[16] "Protean electric courts partners for wheel motor applications," Automotive Engineering Online, Jun. 24, 2010.

[17] "In-wheel electric drive company names EV industry veteran Bob Purcell Chairman and CEO," Green Car Congress, Oct. 6, 2010.

[18] A. Fraser, "In-wheel electric motors: the packaging and integration challenges," in 10th International CTI Symposium, Berlin, Dec. 2011.
[19] J. Stetter, "Siemens saves weight and space with integrated motor and inverter,"Charged Electric Vehicles Magazine, Mar. 17, 2015.

[20] "Siemens integrates EV motor and inverter in single housing; common cooling and SkiN," in Green Car Congress, Aug. 6, 2017.

[21] N. Kaminski and O. Hilt, "SiC and $\mathrm{GaN}$ devices - Wide bandgap is not all the same," in IET Circuits, Devices \& Systems, vol. 8, no. 3, pp. 227-236, May 2014.

[22] J. Millán, P. Godignon, X. Perpiñà, A. Pérez-Tomás, and J. Rebollo, "A survey of wide bandgap power semiconductor devices," in IEEE Transactions on Power Electronics, vol. 29, no. 5, pp. 2155-2163, May 2014.

[23] S. Häuser. (2016, April). Is only full SiC the "Real" SiC? Semikron Inc, Nuremberg. Germany. [Online].Available: https://www.semikron. $\mathrm{com} / \mathrm{dl} /$ service-support/downloads/download/semikron-article-is-only-full-sic-the-real-sic-en-2016-04-01/.

[24] Rohm (2014, August). SiC power devices and modules application note. Rohm Inc. Kyoto, Japan. [Online]. Available: http://rohmfs. rohm.com/en/products/databook/applinote/discrete/sic/common/sic appli-e.pdf.

[25] H. R. Chang, E. Hanna, and A. V. Radun, "Development and demonstration of silicon carbide ( $\mathrm{SiC}$ ) motor drive inverter modules,"in Power Electronics Specialist Conference, 2003. PESC '03. 2003 IEEE 34th Annual, 2003, vol. 1, pp. 211-216.

[26] X. Ding, M. Du, T. Zhou, H. Guo, and C. Zhang, "Comprehensive comparison between silicon carbide MOSFETs and silicon IGBTs based traction systems for electric vehicles," Applied Energy, vol. 194, pp. 626-634, 2017.

[27] A. Agarwal. (2017, February). The revolution in Wide Band Gap (WBG) power devices. [Online]. Available: https://nanohub.org/resources/25890/download/2017.02.08-Agarwal-EE.pdf.

[28] J. Wang, "Design of multilevel integrated modular motor drive with gallium nitride power devices," $\mathrm{PhD}$ dissertation, The University of Wisconsin-Madison, Madison, US, 2015.

[29] R.W. Erickson and M. Dragan. in Fundamentals of Power Electronics, Springer Science \& Business Media, 2007, pp. 80-81.

[30] D. Han, W. Lee, J. Noppakunkajorn, and B. Sarlioglu, "Investigating the influence of interconnection parasitic inductance on the performance of SiC based DC-DC converters in hybrid vehicles," in 2014 IEEE Transportation Electrification Conference and Expo (ITEC), Dearborn, MI, 2014, pp. 1-7.

[31] K. Olejniczak et al, "Advanced low-cost $\mathrm{SiC}$ and $\mathrm{GaN}$ wide bandgap inverters for under-the-hood electric vehicle traction drives," $D O E$ Merit Review, Jun. 8, 2016.

[32] K. Olejniczak et al., "A compact $110 \mathrm{kVA}, 140^{\circ} \mathrm{C}$ ambient, $105^{\circ} \mathrm{C}$ liquid cooled, all-SiC inverter for electric vehicle traction drives," in 2017 IEEE Applied Power Electronics Conference and Exposition (APEC), Tampa, FL, 2017, pp. 735-742.

[33] Mitsubishi. (2017, March). Mitsubishi electric develops world's smallest $\mathrm{SiC}$ inverter for HEVs. Mitsubishi Corp., Tokyo, Japan. [Online]. Available: http://www.mitsubishielectric.com/news/2017/0309-a.html.

[34] S. Jahdi, O. Alatise, C. Fisher, L. Ran, and P. Mawby, "An evaluation of silicon carbide unipolar technologies for electric vehicle drivetrains," in IEEE Journal of Emerging and Selected Topics in Power Electronics, vol. 2, no. 3, pp. 517-528, Sept. 2014.

[35] A. Stefanskyi, L. Starzak, and A. Napieralski, "Silicon carbide power electronics for electric vehicles," 2015 Tenth International Conference on Ecological Vehicles and Renewable Energies (EVER), Monte Carlo, 2015, pp. 1-9.

[36] Z. Liang, "Packaging technologies to exploit the attributes of WBG power electronics," in 2014 IEEE Workshop on Wide Bandgap Power Devices and Applications, Knoxville, TN, 2014, pp. 1-73.

[37] J. B. Cassady, "Silicon Carbide in Automotive," in Power Electronics Europe, issue 3, May 2014, pp. 26-28.

[38] S. M. Muyeen, "Wind energy conversion systems - Technology and trends," Springer, 2012, pp. 104-105.

[39] Z. Wang et al., "A high temperature silicon carbide mosfet power module with integrated silicon-on-insulator-based gate drive," IEEE Transactions on Power Electronics, vol. 30, no. 3, Mar. 2015, pp. $1432-1445$.

[40] P. W. Wheeler et al., "An integrated $30 \mathrm{~kW}$ matrix converter based induction motor drive," in 2005 IEEE 36th Power Electronics Spe- 
cialists Conference, Recife, 2005, pp. 2390-2395.

[41] B. J. Sykora, "Development of a demonstrator model of an integrated modular motor drive," M.S. thesis, Dept. of Electr. and Computer Eng., University of Wisconsin- Madison, Madison, US, 2008.

[42] R. J. White, T.M. Jahns, and T.A Lipo, "Fault management techniques for an integrated modular motor drive," in Proc. of 2005 CPES Power Electronics Seminar, Blacksburg, VA., Apr. 2005, pp. 581-588.

[43] B. J. Sykora, T. M. Jahns, and R. D. Lorenz. "Development of a demonstrator model of an integrated modular motor drive." in Proc. 2008 NSF-CPES Annual Conference, Blacksburg, VA., 2008.

[44] G. Choi et al., "Development of integrated modular motor drive for traction applications." in SAE International Journal of Engines 4, 2011, pp.286-300

[45] S. I. Mueller, "Model and design of an air-cooled thermal management system for an integrated motor-controller," M.S. thesis, University of Wisconsin--Madison, Madison, USA, 2005.

[46] A. Shea and T. M. Jahns, "Hardware integration for an integrated modular motor drive including distributed control," in 2014 IEEE Energy Conversion Congress and Exposition (ECCE), Pittsburgh, PA., 2014, pp. 4881-4887.

[47] A. Shea and T. M. Jahns, "Control challenges and mitigation techniques for sensor errors in modular motor drives with weakly-coupled distributed control architectures," in 2015 IEEE International Electric Machines \& Drives Conference (IEMDC), Coeur d'Alene, ID, 2015, pp. 890-896.

[48] J. Wang, Y. Li, and Y. Han, "Integrated modular motor drive design with GaN power FETs," in IEEE Transactions on Industry Applications, vol. 51, no. 4, Jul.-Aug., 2015, pp. 3198-3207.

[49] P. Yi, P. K. S. Murthy, and L. Wei, "Performance evaluation of SiC MOSFETs with long power cable and induction motor," in 2016 IEEE Energy Conversion Congress and Exposition (ECCE), Milwaukee, WI, 2016, pp. 1-7.

[50] D. Han, S. Li, Y. Wu, W. Choi, and B. Sarlioglu, "Comparative analysis on conducted CM EMI emission of motor drives: WBG versus Si devices," in IEEE Transactions on Industrial Electronics , vol. 99, 2017, p.1.

[51] R. J. Kerkman, D. Leggate and G. L. Skibinski, "Interaction of drive modulation and cable parameters on AC motor transients," in IEEE Transactions on Industry Applications, vol. 33, no. 3, May/Jun. 1997, pp. 722-731.

[52] Z. Zhang, F. Wang, L. M. Tolbert, B. J. Blalock, and D. J. Costinett, "Evaluation of switching performance of SiC devices in PWM inverter-fed induction motor drives," in IEEE Transactions on Power Electronics, vol. 30, no. 10, Oct. 2015, pp. 5701-5711.

[53] B. Wu, S. B. Dewan, and G. R. Slemon, "PWM-CSI inverter for induction motor drives," in IEEE Transactions on Industry Applications, vol. 28, no. 1, Jan/Feb. 1992, pp. 64-71.

[54] J. Waldron and T. P. Chow, "Physics-based analytical model for high-voltage bidirectional $\mathrm{GaN}$ transistors using lateral $\mathrm{GaN}$ power HEMT," 2013 25th International Symposium on Power Semiconductor Devices \& IC's (ISPSD), Kanazawa, 2013, pp. 213-216.

[55] D. Bergogne et al., "Demonstration of the normally-off bi-directional GaN AC switch," in 2016 International Conference on Electrical Systems for Aircraft, Railway, Ship Propulsion and Road Vehicles \& International Transportation Electrification Conference (ESARS-ITEC), Toulouse, 2016, pp. 1-4.

[56] S. Mori et al, "Demonstration of $3 \mathrm{kV} 4 \mathrm{H}-\mathrm{SiC}$ reverse blocking MOSFET," in Proc. of 2006 IEEE International Symposium on Power Semiconductor Devices and ICs (ISPSD), Prague, Jun. 2016.

[57] C. Vadstrup, X. Wang, and F. Blaabjerg, "LC filter design for wide band gap device based adjustable speed drives," in 2014 International Power Electronics and Application Conference and Exposition, Shanghai, 2014, pp. 1291-1296.

[58] Y. Zhang, W. Zhang, and T. M. Jahns, "Investigation of single-switch short-circuit fault characteristics of a PM machine drive with a current source inverter," in 2015 IEEE International Electric Machines \& Drives Conference (IEMDC), Coeur d'Alene, ID, 2015, pp. 967-973.

[59] Z. Wu and G. J. Su, "High-performance permanent magnet machine drive for electric vehicle applications using a current source inverter," in 2008 34th Annual Conference of IEEE Industrial Electronics, Orlando, FL, 2008, pp. 2812-2817.
[60] D. C. Katsis and Y. Zheng, "Development of an extreme temperature range silicon carbide power module for aerospace applications," in 2008 IEEE Power Electronics Specialists Conference, Rhodes, 2008, pp. 290-294.

[61] P. Ning et al., "SiC Wirebond multichip phase-leg module packaging design and testing for harsh environment," in IEEE Transactions on Power Electronics, vol. 25, no. 1, Jan. 2010, pp. 16-23.

[62] S. Seal and H. A. Mantooth, "High performance silicon carbide power packaging - past trends, present practices, and future directions," Energies, vol. 10, pp. 1-30.

[63] M. Schneider-Ramelow, et al. "Technologies and trends to improve power electronic packaging," in Proceedings of the 44th International Symposium on Microelectronics, Long Beach, CA, 9-13 October 2011; pp. 430-437.

[64] M. Horio, Y. Iizuka, Y. Ikeda, E. Mochizuki, and Y. Takahashi, "Ultra compact and high reliable $\mathrm{SiC}$ MOSFET power module with $200^{\circ} \mathrm{C}$ operating capability," in 2012 24th International Symposium on Power Semiconductor Devices and ICs, Bruges, 2012, pp. 81-84.

[65] S. Seal, M. D. Glover, A. K. Wallace, and H. A. Mantooth, "Flip-chip bonded silicon carbide MOSFETs as a low parasitic alternative to wire-bonding," in 2016 IEEE 4th Workshop on Wide Bandgap Power Devices and Applications (WiPDA), Fayetteville, AR, 2016, pp. 194199.

[66] U. Scheuermann, "Reliability of planar SKiN interconnect technology," in 2012 7th International Conference on Integrated Power Electronics Systems (CIPS), Nuremberg, 2012, pp. 1-8.

[67] K. Weidner, M. Kaspar, and N. Seliger, "Planar interconnect technology for power module system integration," in 2012 7th International Conference on Integrated Power Electronics Systems (CIPS), Nuremberg, 2012, pp. 1-5.

[68] S. Eicher et al., " $4.5 \mathrm{kV}$ press pack IGBT designed for ruggedness and reliability," in Conference Record of the 2004 IEEE Industry Applications Conference, 2004. 39th IAS Annual Meeting., vol.3, 2004. pp. 1534-1539.

[69] Z. Chen, et al. "Development of an $\mathrm{SiC}$ multichip phase-leg module for high-temperature and high-frequency applications." Journal of Microelectronics and Electronic Packaging, vol.13, no.2, 2016, pp. $39-50$.

[70] H. Zhang, S. S. Ang, H. A. Mantooth, and S. Krishnamurthy, "A high temperature, double-sided cooling $\mathrm{SiC}$ power electronics module," in 2013 IEEE Energy Conversion Congress and Exposition, Denver, CO, 2013, pp. 2877-2883.

[71] J. Watson and C. Gustavo, "A review of high-temperature electronics technology and applications." Journal of Materials Science: Materials in Electronics, vol. 26, no.12, pp. 9226-9235, 2015.

[72] J. Bond. (2015, March). ECI high temperature film capacitors. Electronic Concept Inc., IL, US. [Online]. Available: http://www.ecicaps. com/tech-tools/technical-papers/eci-high-temperature-film-capacitors/

[73] C. Bunel and L. Lengignon, "Silicon Capacitors with extremely high stability and reliability ideal for high temperature applications," in International Conference on High Temperature Electronics (HiTEC 2012), Albuquerque, vol. 2013, no. HITEN, Jan. 2013, pp. 8-12.

[74] M. P. Manoharan, M. T. Lanagan, C. Zhou, D. Kushner and S. Zhang, "Enhancement of dielectric breakdown strength in glass using polymer coatings," in 2012 IEEE International Power Modulator and High Voltage Conference (IPMHVC), San Diego, CA, USA, 2012, pp. 280-283.

[75] Microchip. Microchip high-temperature products and solutions. Microchip Inc., AZ, US. [Online]. Available: http://www.microchip.com/ design-centers/high-temperature.

[76] Polymer Engineering Center. Optimized 3D air-side heat transfer surfaces with 500\% heat transfer enhancement. UW-Madison, WI, US. [Online]. Available: http://pec.engr.wisc.edu/rudolph-research.html.

[77] E. M. Dede, M. Ishigaki, S. N. Joshi, and F. Zhou, "Design for additive manufacturing of wide band-gap power electronics components," in 2016 International Symposium on 3D Power Electronics Integration and Manufacturing (3D-PEIM), Raleigh, NC, 2016, pp. 1-20.

[78] G. Moreno (2016, June). Power electronics thermal management R\&D. National Renewable Energy Laboratory, CO., US. [Online]. Available: https://www.nrel.gov/docs/fy16osti/66047.pdf.

[79] K. Ogawa. (2015, December). Toyota cuts PCU cost by $30 \%$ for new 
prius. [Online]. Available: http://techon.nikkeibp.co.jp/atclen/news_ en/15mk/120200210/.

[80] Yole Développement (2015, March). EV-HEV market and technology trends. 2015 IEEE APEC, NC, US. [Online]. Available: http://www. psma.com/sites/default/files/uploads/is24-ev-hev-market-and-technology-trends.pdf.

[81] F. P. McCluskey and A. Bar-Cohen, "Power electronics thermal packaging and reliability," in 2013 IEEE Transportation Electrification Conference and Expo (ITEC), Detroit, MI, 2013, pp. 1-168.

[82] R. Walli. (2014, October) New ORNL electric vehicle technology packs more punch in smaller package. [Online]. Available: https://www.ornl.gov/news/new-ornl-electric-vehicle-technology-packs-more-punch-smaller-package.

[83] J. D. van Wyk, F. C. Lee, "On a future for power electronics," in IEEE Journal of Emerging and Selected Topics in Power Electronics, vol. 1, no. 2, pp. 59-72, Jun. 2013.

[84] T. Ericksen, Y. Khersonsky, P. Schugart, P. Steimer, "PEBB-power electronics building blocks, from concept to reality," in the 3rd IET International Conference on Power Electronics, Machines and Drives (PEMD), Dublin, Ireland, 2006, pp. 12-16.

[85] A. Nakajima et al., "An overview of GaN-based monolithic power integrated circuit technology on polarization-junction platform," in 2015 IEEE Compound Semiconductor Integrated Circuit Symposium (CSICS), New Orleans, 2015, pp. 1-4.

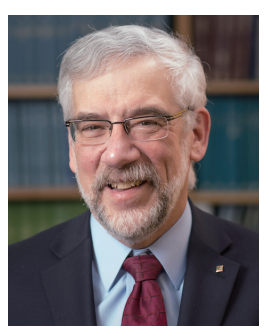

Thomas M. Jahns received his S.B, S.M, and Ph.D. degrees in electrical engineering from the Massachusetts Institute of Technology, Cambridge, MA (USA) in 1974 and 1978.

In 1998, he joined the Department of Electrical and Computer Engineering, University of Wisconsin-Madison, as a Grainger Professor of Power Electronics and Electric Machines, where he is currently a Co-Director of the Wisconsin Electric Machines and Power Electronics Consortium (WEMPEC). Prior to joining UW, he worked at GE Corporate Research and Development (now GE Global Research Center), Niskayuna, NY, for 15 years. From 1996 to 1998, he conducted a research sabbatical at M.I.T., where he directed research activities in the area of advanced automotive electrical systems as Co-Director of an industry-sponsored consortium. His current research interests include high-performance permanent-magnet synchronous machines, electric traction drives, and distributed energy resources, including microgrids.

Dr. Jahns received the 2005 IEEE Nikola Tesla Technical Field Award and the IAS Outstanding Achievement Award in 2011. He has served both the IEEE Industry Applications Society and Power Electronics Society (PELS) as a Distinguished Lecturer. Dr. Jahns is a Past President of PELS and served two years as Division II Director on the IEEE Board of Directors (2001-2002). He was elected as a member of the US National Academy of Engineering in 2015.

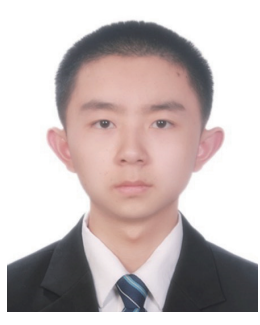

Hang Dai received his B.Eng. degree in electrical engineering and its automation from North China Electric Power University (NCEPU), Beijing, China in 2015. He is currently pursuing his Ph.D. degree in electrical engineering at University of Wisconsin-Madison.

Since 2016, he is a Research Assistant with Wisconsin Electric Machines and Power Electronics Consortium (WEMPEC). His research interests include power electronics and electric machines, with special focus on wide-bandgap-based current-source and voltage-source inverters for integrated motor drive applications.

Mr. Dai was a recipent of NCEPU Excellent Admitted Students and Outstanding Graduates Awards in 2011 and 2015, respectively, China Scholarship Council (CSC) Excellent Undergraduate Grant from 2014-2015, and the Best Innovative Design Award in the 2015 IEEE International Future Energy Challenge Competition. 